\title{
Manufacturing System Performance Improved through Enterprise Resource Planning in Supply Chain Management On Shop Floor of Firms
}

\author{
${ }^{1}$ Rajendra Singh \\ I. (Assoc. Prof.) \\ ${ }^{2}$ Munish Kumar \\ 2.(PhD Scholar) \\ ${ }^{3}$ Vikas Kumar \\ ${ }^{3}$ (Asst. Professor) \\ ${ }^{I}$ (Department of Mechanical Engineering, Aryan Institute of Technology, Jindal Nagar, Ghaziabad, U. P.) \\ ${ }^{2}$ (National Institute Of Technology, Jallandhar, Punjab) \\ ${ }_{3}^{3}$ (Department of Mechanical Engineering, NIMS University, Jaipur, Rajasthan)
}

\begin{abstract}
Many production facilities generate and update production schedules on shop floor for manufacturing. Rescheduling is necessary because the manufacturing system is dynamic and unexpected events occur. This research paper discusses Enterprise Resource Planning in Supply Chain Management policies and how they affect the performance of manufacturing systems. The benefits of proper Enterprise Resource Planning in Supply Chain Management include improved manufacturing system performance with reduced cost due to computational effort human or computer and disruptions to existing plans (nervousness). The paper summarizes previous work in this area and also discusses how it requires methods to solve production problems on shop floor. The goal is to help production planners, engineers, and researchers understand the importance of Enterprise Resource Planning in Supply Chain Management and the proper role of production in dynamic manufacturing systems. Enhanced competitiveness requires that companies ceaselessly integrate within a network of organizations. Firms ignoring this challenge are destined to fall behind their rivals. This integration of companies within a network has led to put more emphasis on Enterprise Resource Planning in Supply Chain Management. The main finding is that the panel experts saw only a modest role for ERP in improving future supply chain effectiveness and clear risk it actually limiting progress in SCM. ERP was seen as offering a positive contribution to future supply chain issues: 1.More customization of products and services, 2.More standardized processes and information, 3. The need for worldwide IT systems, and 4.Greater transparency of the market palace. Implications for research and management practice are discussed.
\end{abstract}

Keywords: - Manufacturing system, Enterprise resource planning, Integrated ERP in SCM model, Supply Chain Management and role of ERP and case study.

\section{INTRODUCTION}

Manufacturing facilities are complex, dynamic, stochastic systems. From the beginning of organized manufacturing, workers, supervisors, engineers, and managers have developed many clever and practical methods for controlling production activities. Although dispatching rules, kanban cards, and other decentralized production control policies are in use, many manufacturing facilities generate and update production schedules, which are plans that state when certain controllable activities (e.g., processing of jobs by resources) should take place. Dispatching rules are usually quick but myopic because they typically they do not use global information. Production schedules can enable better coordination to increase productivity and minimize operating costs. A production schedule can identify resource conflicts, control the release of jobs to the job shop, ensure that required raw materials are ordered in time, determine whether delivery promises can be met, and identify time periods available for preventive maintenance. Production scheduling is a very difficult combinatorial optimization problem, so manual solution of any reasonably large problem is impossible. Research scientists, software companies, and manufacturing consultants have developed and implemented advanced scheduling systems that can perform production scheduling for complex manufacturing systems. These scheduling systems exploit results from production scheduling theory and advanced optimization techniques. Moreover, because the manufacturing system is dynamic and unexpected events occur, rescheduling is necessary because the production schedule is a plan that must be updated when the state of the manufacturing system makes the current production schedule infeasible. There are many types of disturbances that can upset the plan, including machine failures, processing time delays, rush orders, quality problems, and unavailable material. As Bean et al. (1991) state, rescheduling is a dynamic approach that responds to disruptions, yet it considers future information by creating a plan for the future. Rescheduling is related to order release. Rescheduling can occur without order release when revising an existing schedule (to respond to a disruption). Order release makes an order available for processing and is thus the same as a job arrival. If order releases (job arrivals) are not predictable, processing cannot begin until the job is scheduled, so either rescheduling must be done when the job arrives or the job must 
wait until the next rescheduling point. If order releases are known ahead of time, then the arriving jobs can be scheduled along with the existing backlog. Most rescheduling research has studied methods for updating a schedule or creating that a schedule that is robust with respect to disturbances. There have also been a few studies that provide guidance on when rescheduling should be done. Traditionally the rescheduling period is based on management measurement periods (one week or one day or one shift). But rescheduling also occurs during this period as unexpected events occur. Task start times are delayed, jobs are reassigned to different resources, and other adjustments take place. Intuitively, one can see that while small disruptions may (or should) be ignored (or handled in some simple way), larger disruptions may require significant changes to the production schedule to maintain good system performance. Huge disruptions will require many changes. This paper discusses rescheduling policies and how they affect the performance of manufacturing systems. The paper summarizes previous work in this area and also discusses how rescheduling requires methods to solve production scheduling problems. The goal is to help production planners, engineers, and researchers understand the importance of rescheduling and the proper role of production scheduling in dynamic manufacturing systems. This paper does not address the sequencing of parts processed in high-volume, repetitive manufacturing systems. In such settings, one can look to JIT and lean manufacturing principles for how to control production. These approaches generally do not need the same type of production schedules discussed here. The remainder of this paper is organized as follows: Section provides definitions for some terms to be used, discusses related work on the control of manufacturing systems, discusses how rescheduling affects manufacturing system performance, discusses the need to solve production scheduling problems. Section 6 concludes the paper and identifies some promising research directions.

It has been two decades since the internal operations are being streamlined, manufacturing boost up, quality of the products are being improved, the costs of manufacturing are being reduced but now the companies are now focusing on the reduction of logistics by mean of putting right supply chain strategies for the excellence of organizations. The statistics show that the logistics costs in European organizations ranged between the 5\% to the highest ratio of $15 \%$ of the total budget or the turnover of the company (AT Kearney, 1993). In the USA, the businesses have spent more than $\$ 670$ billion on the supply chain related activities during the year 1993 which was the $10.5 \%$ of the total GDP (Kurt Salmon, 1993). The other key reason for the modifications that are regularly made in the scope and methodologies of the supply chain management (SCM) is the advent of the network economy (Castells, 1996; Arthur, 1996). Nowadays, there is more transparency in the markets where there is more customization added to the demands of the customers (Jensen, 1999). However, it has been noticed that there is always an increment in the prices for the business world (Gleick, 1999). The developments in the supply chain management (SCM) can have a great impact on the businesses. There is a rapid growth in the literatures that are being published about the models for new business following the age of internet however, most of them have stressed upon the fact that supply chain management is also enlisted as competency element with the growing competition in the business. It is also interesting the Enterprise Resource Planning (ERP) is also growing in the business where the businesses are starving to make improvements in their supply chain management based operations. Enterprise Resource Planning is also considered as an extension of the Market Requirement Planning (MRP) which is being launched during the 1970s and also the manufacturing Resource Planning (MRP II) which was introduced in the next decades of 1980s.

There are two major considerations which are held responsible for this development in the simultaneous manner. The first consideration that is noticed is marked as like the decisions which are managerial based are considered to be the closed linking factors for the two separate prospective. There evolution in the industry is considered as industrial (White et. Al.,1999).

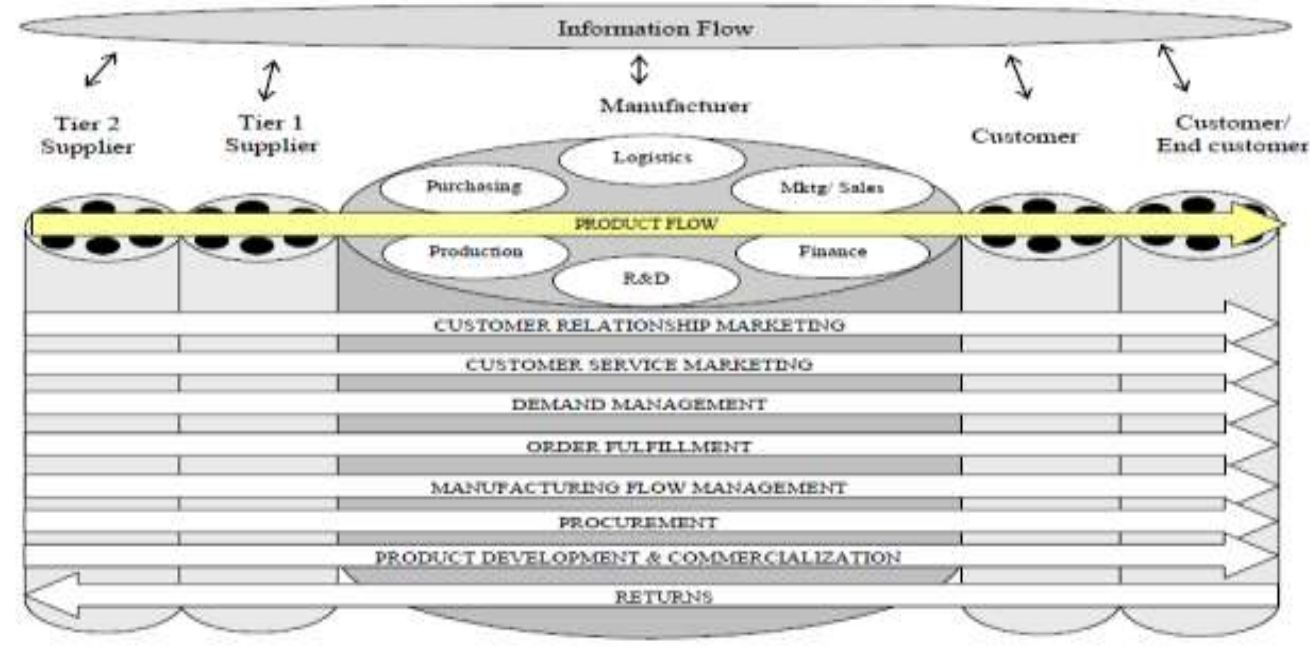


Figure 1.: Integrated system of Manufacturing system ,ERP and SCM

THEORETICAL BACK GROUND OF MANUF. SYSTEM ON SHOP FLOOR

To avoid the possibility of confusion, let us define some terms before continuing. A manufacturing system organizes equipment, people, and information to fabricate and assemble finished goods that are shipped to a customer. This system may be as large as a factory or as small as a manufacturing cell. According to Black (2000), a manufacturing system is "the collection of operations and processes used to produce a desired product." A manufacturing system does not include finance, design engineering, research and development, production and inventory planning, purchasing, or distribution. Note that it does include order release, shop floor control, and material handling.

Order release controls a manufacturing system's input by determining which orders (jobs) should be moved into production. It may be known as job release, order review/release, input/output control, or just input control.

Shop floor control determines which operation each person and piece of equipment should do and when they should do it. In general this process controls all production and material handling resources. Design decisions include order release policies (including WIP levels for pull systems), dispatching rules, batch sizes, and preventive maintenance policies.

A production schedule specifies, for each resource required for production, the planned start time and end time of each job assigned to that resource.

Scheduling is the process of creating a production schedule for a given set of jobs and resources.

Rescheduling is the process of updating an existing production schedule in response to disruptions or other changes. This includes the arrival of new jobs, machine failures, and machine repairs.

A rescheduling policy specifies how rescheduling is done. The policy specifies the events that trigger rescheduling. These events may be predictable (even regular) or unpredictable. The policy specifies the method used to revise the existing schedule. Note that the policy may specify different methods for different situations. If these policies have any parameters (for instance, the length of the rescheduling period), the policy specifies these parameters.

Dynamic scheduling schemes do not create production schedules. Instead, these decentralized production control methods dispatch jobs when necessary and use all information at the moment of dispatching. Such schemes use dispatching rules to prioritize jobs waiting for processing at a resource.

Bill of Materials Management: BOM management is a very core and the critical part while maintaining the product structure throughout the lifecycle of a product. Engineering organizations can leverage the conceptual product architecture definitions to generate configured products that satisfy market specifications, and provide many possible optional capabilities. These conceptual product definitions serve as a framework for defining variant products that are configurable and drive the generation of engineering bills-of-material (EBOMs). As a result, companies can expedite the design process and lower costs while still meeting customer demands. Organizations find BOM management tools helpful in mitigating the difficulties of product sharing between the manufacturing and engineering departments. The engineering project manager, who must estimate costs and analyse engineering tasks, is generally the first member of the organization to compile the BOM. The manufacturing department, who uses the BOM to build the product, is not often involved in the creation of the BOM. This handoff can present a challenge if the parties giving and receiving product data are not on the same page. A BOM management tool can help combine input from engineering and manufacturing teams and ensure both teams work from the same product data.

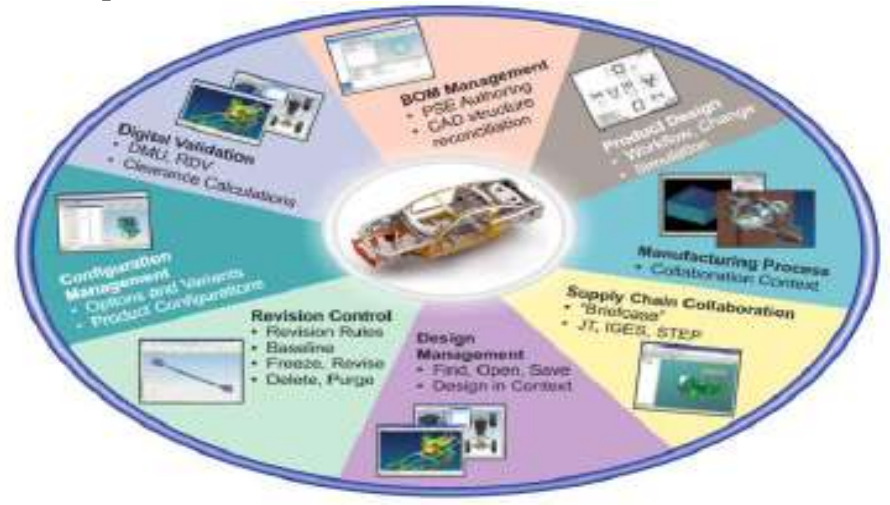

Figure 2.: Collaboration in different departments

looking for a BOM management tool, it is important to invest in a tool that will support both short-term and long-term product development strategies.

PLM Bill of materials management software is a critical part of the design and manufacture of any product. If you work for a leading company, you understand this and are, on average, two-times more likely to leverage centralized product data to improve product configuration management. Through effective BOM management, 
you can provide tailored visibility to central product information by role, and extend configuration management beyond the BOM to include a richer product definition. The results speak for themselves. According to a 2007 Aberdeen Group report, companies that employ an effective BOM management software solution are able to hit product development and lifecycle targets 89 percent of the time or more (on average), versus 30 to 40 percent of the time for laggards.

Related Work: BOMs don't belong in spreadsheets. Innovate with confidence knowing everyone has the right version of the BOM is very necessary. Out of all the PLM tools, Team center and Enovia are the two leading softwares which give the solution to PLM as per the needs of a customer. However, even if they give the solution to a business organization, the actual implementation of the PLM that they implement is not open source. Each of the mentioned softwares needs a license to run the solutions. Here, we will study bill of material management general architecture implemented in Teamcenter as well as Enovia. Further, we will narrow it down to a specific variant bill of material management.

Team center Variant Bill of Materials Management: Team center has bill of material management solutions can help the company deliver new product offerings and derivatives from a single platform of common technologies, product structures and automated processes. Teamcenter creates product platforms that are used to minimize the take-to-market costs, accelerate the startup processes, and maximize the revenue generated by a product's initial release - as well as by its successors and derivatives.

Siemens has developed PLMXML which is an emerging format for facilitating product lifecycle interoperability using XML.As the design process moves from early development through the handoff to production, a BOM can become increasingly complex and difficult to maintain-especially for organizations who do not have a proper BOM management tool. Frequently, engineering project managers have to create and maintain several versions of the BOM to meet the needs of different audiences. Without a dedicated BOM management tool to handle continually evolving versions of the BOM, product data sharing can be a time consuming and tedious task, not to mention error prone.

\section{The Need to Solve Scheduling Problems}

Rescheduling provides a perspective that can put into proper context the need to solve production scheduling problems in dynamic, stochastic manufacturing systems. Rescheduling policies identify not only when rescheduling should be done but also the objectives and constraints of the resulting scheduling problem. For example, Bean et al. (1991) present the matchup scheduling problem, which attempts to recover the original schedule as soon as possible while satisfying a constraint on allowable tardiness cost. Vieira et al. (2000a, b) study rescheduling policies that require the production schedule to minimize the number of setups and the job flow time. Portougal and Robb (2000) discuss the gap between production scheduling theory and practice and emphasize the importance of the planning period. Their paper argues that, if job cycle times are greater than the planning period, then careful scheduling is needed to coordinate activities in multiple planning periods, and complex models are appropriate. If the cycle time is smaller, then scheduling is seldom important. The paper states that, in the latter case, the only important objective is that the resource (or production unit) completes all of the desired work in the planning period. Despite that claim, however, one can easily see that scheduling is indeed important if careless scheduling would prevent the resource (or production unit) from accomplishing this goal. In the presence of sequence-dependent setup times, for instance, scheduling significantly affects the total time required. A poor schedule would waste valuable time doing setups. Thus, it may be more appropriate to state that, when job cycle times are shorter than the planning period, satisfying the production target should set the constraints and objectives of the production scheduling problem. The resulting production scheduling problems may emphasize finding feasible solutions over optimization, but such problems can be extremely difficult in realistic settings.

Common factors identified in re-scheduling:-

- Machine failure

- Argent job arriaval

- Job cancelation

- Due date change

- Delay in arrival or shortage of materials

- Change in job priority

- Rework or quality problems

- Over or underestimation of process time

- Operator absenteeism.

Other action sugested rescheduling

- Over time

- In process subcontracting

- Process change or rerouting

- Machine substitution

- Limited manpower

- Set up times
- Equipment release.

$4 \mid \mathrm{P}$ a g e 
Historical Background

\section{ENTERPRISE RESOURCE PLANNING (ERP)}

Enterprise Resource Planning (ERP) took its start in the late 1980's and then properly extended in the 1990's whereas the large area of focus was the huge scale business organizations. These systems are considered as complex, they are expensive, they are powerful while these systems were also considered as the key platform for simplifying the complex operations. On the other hand, there are certain limitations that are accompanied modifications that make companies bound to make changes in the complete operational system of the business to make an adjustment with the module of the software.

\section{Business impacts of ERP on SCM trends:}

The following figure contains the output of our workshop script in which, it was a simple form of multi-criteria analysis. It shows the aggregate scores of each of the top 12 SCM trends. The expected business impact of each trend and the degree to which ERP could be expected to support of this trend.

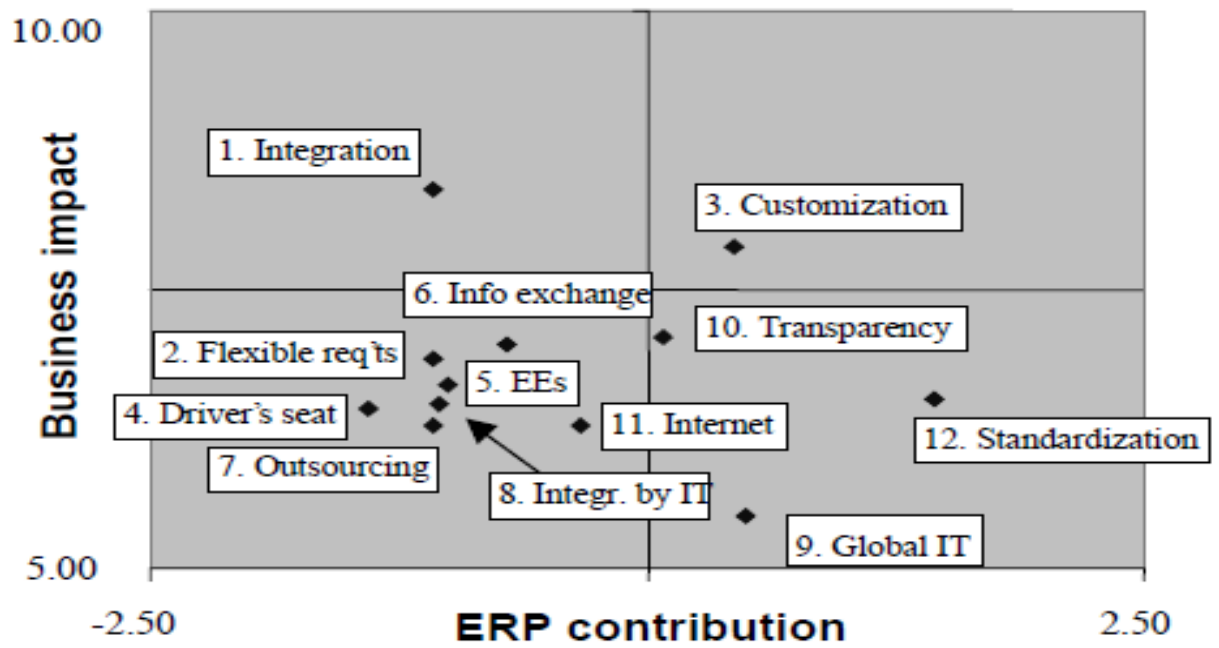

Figure 3.1 : Business impact of SCM initiatives and ERP's contribution.

\section{Research Objectives}

The research is being conducted following these research objectives:

I. To analyze the role of Enterprise Resource Planning (ERP) in the enhancement of operations within the organization to improve the Manufacturing System Performance.

II. To analyze the role of Enterprise Resource Planning (ERP) in the enhancement of operations being out bounded by the organization to improve the Manufacturing System Performance .

III. To analyze the support of Enterprise Resource Planning (ERP) towards the Supply Chain Management (SCM) operations to improve the Manufacturing System Performance.

IV. To analyze the role of Enterprise Resource Planning (ERP) in the decision making in Supply Chain Management (SCM) to improve the Manufacturing System Performance .

\section{Aim of Research}

The purpose of this research is to continue in this field of study and solve real problems with ERP implementation, and eventually create analytical tools for these systems. With the advent of globalization ERP software has emerged as a major area of interest for many business organizations. As companies are more and more interested to implement ERP systems into the companies, the need for proper implementation of the same has increased as well. The very advantage of the ERP itself can be described as its main disadvantage. ERP allows easy access to reliable integrated information but whereas its biggest disadvantage is its integration of its system which is the basic problem in its implementation. Some researchers indicate that ERP won't be able to make decision by itself, and some others say for making decisions based on information stored in ERP, the integrity of the system and algorithm optimization is inevitable.

On the other hand the whole system processes and data integration organization is always necessary tools for supply chain management and prerequisite for implementing its process. Application for supply chain process modeling in analytical layer, which must interact with ERP used to improve the performance of manufacturing systems, will cause to implementing standard processes and supply chain collaboration. This research tries to bring out how information transparency impact on enterprise business process and thereby reduce operational cost. This research also aims to study about the ERP effects in supply chain decision making, and precisely ERP's role on implementing standard supply chain process and SCM collaboration. This research 
paper also study about supply chain problems and how to improve supply chain performance indicators by implementation ERP to improve the overall performance of the manufacturing systems.

\section{Significance of the Research Study}

ERP plays a major role in Vendor Managed Inventory. A vendor managed inventory (VMI) is a process where the manufacturer generates order for the manufacturer based on the demand created by the distributor using ERP. During this process the manufacturer follows mutually agreed objectives between the manufacturer and distributor for filling rates and transaction costs. In this regard, some ordering model in Vendor Managed Inventory (VMI) for the retail industry will be discussed, and its effect on supply chain collaboration mechanism is reviewed, and finally the process cost reduction as a supplier, will be discussed as operational model and rate of this quantities improvement is measured.

There have been numerous researches in the field of ERP and its advantages on its implementation. Our focus is to bring out how important is to integrate ERP into the whole system so that the system can yield long term benefits in long run. The reason we stress how important is because ERP implementation is like a big bang effect which changes the activity of the whole organization and proper understanding of the system and cooperation for implementation of the system between the members of the organization are very important because humans are prone to change but a change as big as an implementation of ERP is not very easily acceptable. Therefore we bring out how beneficial can be ERP on a larger scale like organizational decision making and proper management of the supply chain. Also our important aim is to bring out the benefits of ERP in cost reduction during ordering especially regarding VMI.

\section{Theoretical And Methodological background}

The methodology adapted to this work was to gather information from various text books, articles and various kinds of reliable information from different companies and many other reliable sources. Some of our older interviews with various Logistics Managers for our previous colleges and present companies work have been instrumental in constructing this research work. The interdependency of ERP,SCM and manufacturing systems has been backed up by various articles and we have chosen few of those articles depending upon our objective and goal. After getting the information and data from various literatures and from various other sources, we have analyzed our information sources critically depending upon the needs of the research work to get our result on the basis of this information. We have narrowed down our result in essay form in our Result chapter which will help resolve confusion of many readers which was one of our priorities. We have also provided a list of our sources along with references for the reader to provide with more information on how we arrived at our result.

This paper in terms of target considered as applied investigation, and has descriptive approach because of modeling and some mathematical tools that is applied. In this study after reviewing the role of enterprise resource planning systems on mechanisms of cooperation in supply chain, the information infrastructure of VMI cooperation Mechanism and integrated supply chain model, and also information sharing effect on supply chain decision-making in these areas, will be discussed.

In next, the past researches about ERP effect on over organizational decision and supply chain will be reviewed. In third, the role of enterprise resource planning system on cooperation mechanism will be analyzed. In Analysis ordering model for supply chain distribution mechanism under VMI mechanism, will be reviewed. And in final discussion and conclusion about the developed model and usage of used methods in future will be reviewed.

\section{Validity and Reliability:}

This study has been an effort to bring out the importance of unknown factors of ERP system which inherits both advantages and disadvantages and also its disabled functions in large scale organizations. The work has been developed closely relative to the available information from various trusted sources. The reference list for various sources has been stated in the research work and therefore the information provided in this work is valid information's. However the reliability of the information is to be tested in real scale for future work which will take an extended amount of time considering the time given for the thesis work. But we are very sure to state that the information and results developed are reliable except that the fact it is not been tested in real time environment.

\section{Research road maps:}




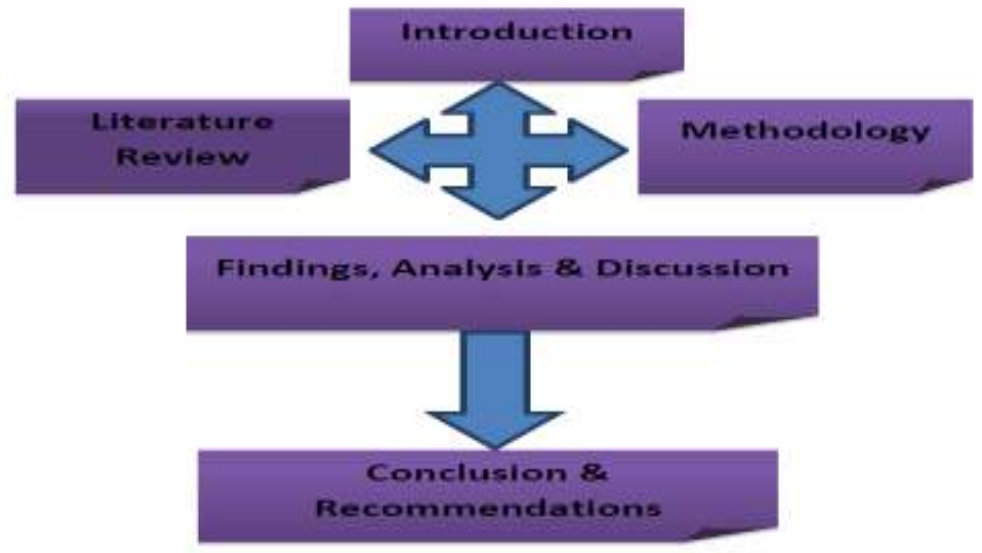

Figure 3.2: Research road maps

\section{SUPPLY CHAIN MANAGEMENT AND ROLE OF ERP}

In this, firstly we will deal with the advantages gained by implementation of ERP over the supply chain management and a detailed perspective view is described over how ERP systems helps making organizational decisions. Then we will be dealing with the concepts of coordination, cooperation and integration in the supply chain which forms the main base for our research question. And then we will proceed by considering cooperative mechanisms including vendor managed inventory (VMI). Subsequently, we will examine the role of ERP systems in creating the information structure, process support and cooperative mechanisms in the supply chain. In this respect, we shall consider the underlying informational and procedural structure required to implement the VMI mechanism.

\section{Supply Chain Management in Network Economy}

Supply chain is a network which consists of suppliers, manufacturers, distributors, customers and many others. There are three types of flow which needs close co- operation and co-ordination.

Material flow - This is a physical flow which represents the movement of product from supplier to customers as well as the movement of product from customers to suppliers in case of servicing, repairing and etc.

Information flow - This is a flow of information which represents the transmission of orders, tracking of orders and etc. This information flow is always co-ordinated with the physical flow of goods.

Financial flow - this flow represents the credit terms, payments and consignments and other ownership arrangements. This flow requires highest level of co - operation between the members of the supply chain (Silver, Pyke and Peterson 1998).

All these networks are in turn supported by the three main pillars. They are

1. Processes which determine the firm's ability to manage logistics develop new product and knowledge management.

2. Organizational structure which determines the relationship between the various members across the supply chain. This structure can be classified as vertical integration and horizontal integration.

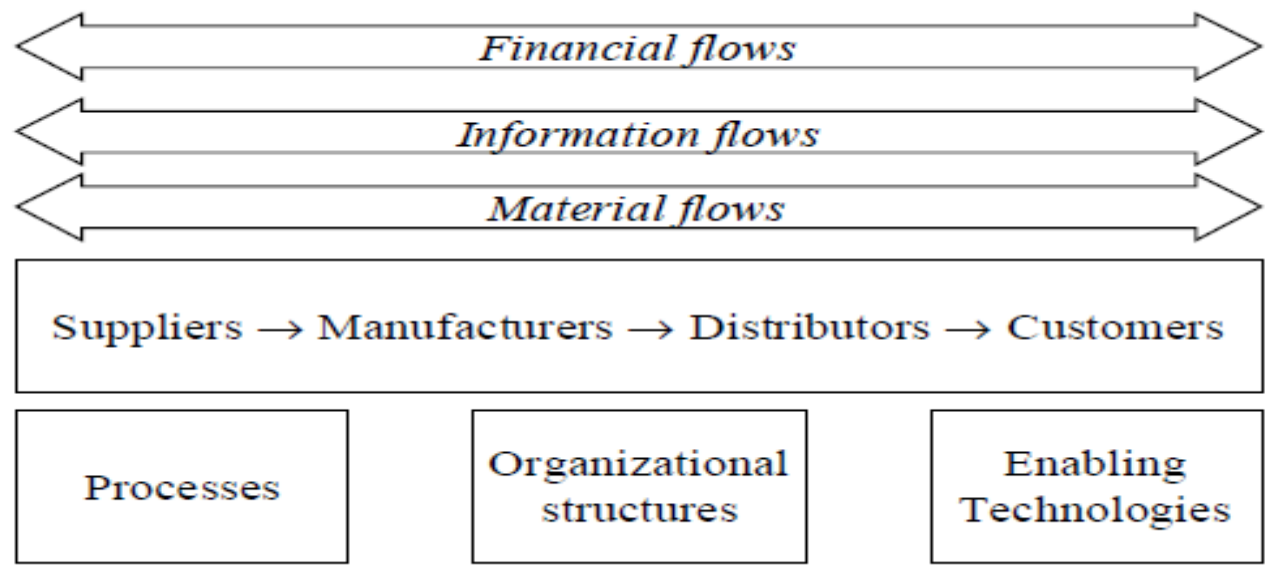

Figure 4.1 : Integrated model of supply chain management. 
Technologies used by the companies which help in easing out the operations related to process and organizational management (Hillier and Lieberman, 2005).

\section{Benefits of ERP on Supply Chain Management}

An $n$ ERP system can offer high value to any organization whose aim is smooth planning and execution of related operations to achieve long term profitability and maintain a solid competitive edge. This is the main reason more and more companies are attracted towards purchasing and implementation of the information technologies like ERPs. What does an ERP has to offer an organization?

Improved Supply Chain Network: ERP provides complete visibility across the supply chain network which is highly impossible in the manual process. With the implementation of ERP an organization can monitor all the status and activities of all suppliers, plants, storage facilities and all the members of the supply chain which makes it easy for communication throughout the network. This in turn helps in effective tracking and management of all processes, right from ordering, through manufacturing and shipping of finished goods to the customers. The status of all the operations can be monitored at any time and corrected anytime in case of problems.

I. Minimized delays: Many supply chains which are not configured with the ERP systems have already placed complaints over poor business relationships and as well as loss in business. Some of the general complaints are late shipments from vendors, slow down or crashes on production lines, logistical errors in distribution channels. These all have negative impacts on organization and therefore results in negative impact with the customers who are the main force of attraction for a supply chain. With the implementation of ERP all the activities can be coordinated and executed ensuring higher levels of on time delivery across the chain.

II. Enhanced Collaboration: ERP helps organization to have a control over all the suppliers and distributors. This creates the ability to know what they are doing all the times. ERP bridges the gap between supply chain partners. With ERP all the members across the network can share vital information like demand, forecasting reports, inventory levels, status of production, transportation plans and many more in real time. This type of available real time information makes the supply chain process to run flawlessly (Stevenson, 2007).

III.Reduced Costs: An ERP can help to reduce expenses in many ways. It can help improve inventory management facilitating just in time model or quick response models which eliminates the strain about the availability of raw materials and therefore the need for storing the raw goods can be eliminated.

\section{ERP helps higher officials in Decision Making}

Research has already been done to help get a better understanding of the ERP decision making process. However there still remains concern over the appropriateness of the ERP software. Ability to handle the confusion can only be gained through experience and Managers are posted on their seats based on their level of experience (Iles, 2007). However ERP can help in assisting the officials in decision making. However our topic is debated on how ERP systems can help in decision making and in this section we have put together some of the advantages gained by ERP systems which helps in quick decision making. In the current business environment information is the key resource of an organization. If the organization does not have an effective mechanism that gives the decision makers the needed or the right information at the right time, then the chances of that organization succeeding in the future will remain a mystery.

To stay stable with the changing trends an organization should be up on its toes. Any technology that will help this gathering of information will enhance the chances of organization to stay alive in the market. With the implementation of ERP system, the organization will be able to function as a single entity and caters to the needs of organization as a whole. The strength of an ERP system is integration and automation and that is why implementation of ERP will help in improving accuracy and in better decision making. For example resource management is one of the biggest problems often encountered by the managers and through the information systems, it is possible to address the problems and move the required resource with in shortest possible time. Therefore the process is not stopped and the time is also saved.

\section{Coordination dimensions in the supply chain}

Supply chain management is founded on the fact that an organization may not effectively and efficiently accomplish the whole processes involved in manufacturing a final product out of raw materials. That is why the interrelationships among the supply chain members require coordination so that materials, information and money would circulate appropriately. Malone has provided a general definition for coordination which assumes the coordination to be equivalent with the management of interrelationships among supply chain 
members. Usually, coordination is defined in connection with the concepts of integration and cooperation (Lambert and Cooper, 2000).

Supply chain coordination takes place at three levels. At the first level, coordination takes place through the integration of cross or exo-organizational information. At the second level, supply chain coordination crystallizes in the cooperation of the supply chain members to create a joint coordination in information and materials. Higher levels contain some of the elements from the lower ones. The most advanced level of coordination takes place in the efficient management of information, materials and money to maximize the creation of value in the supply chain (Christopher and Jüttner, 2000). This type of optimal coordination is the result of using the layer coordination model illustrated in figure

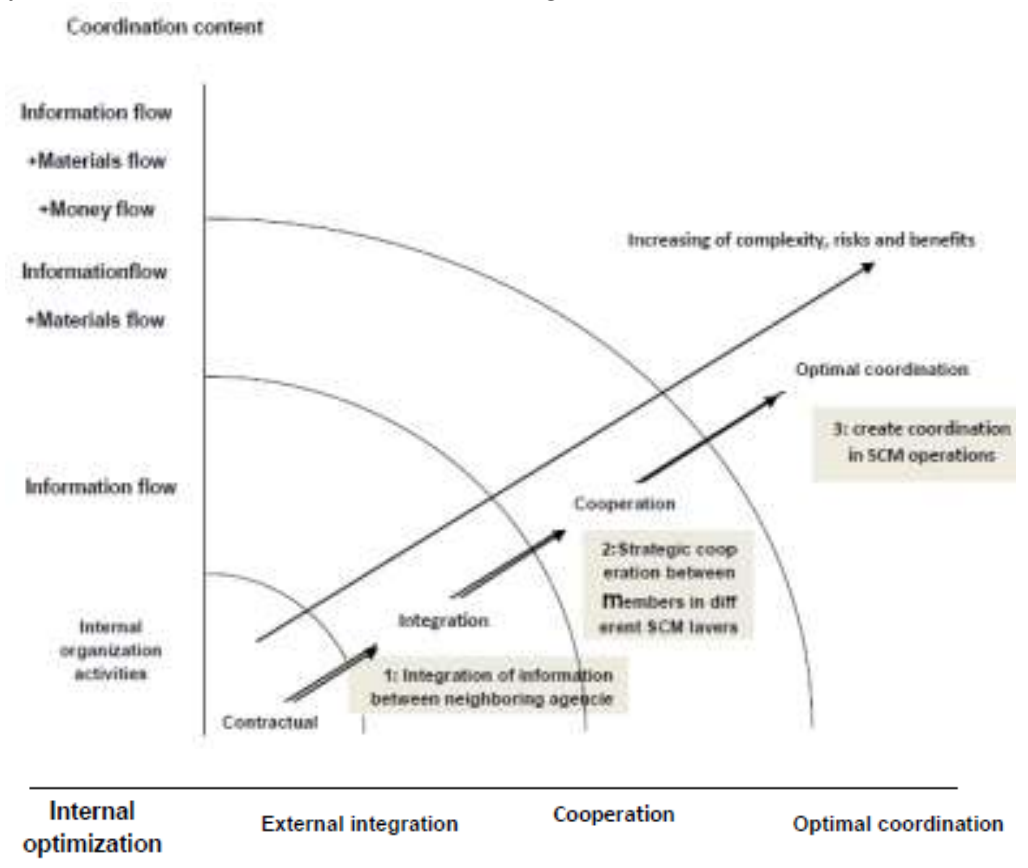

Figure 4.2: Coordination levels in the supply chain

The literature contains a variety of models proposed for coordination in the supply chain. For example, Lee and Whang (2002) suggest a four-level integration in the supply chain including information integration, workflow coordination, synchronization and new business models. In this model, information integration refers to the degree to which such information as demand information, supply status, capacity planning and transport planning is shared. Coordination in the supply chain often denotes a joint planning to forecast and compensate for the product. In the literature, however, the word "cooperation" is used to describe this concept. The fourth dimension of integration in this model involves new business models which indicate the know-how of production and development of new products in cooperation with the whole chain members as well as developing a tendency of "mass production based on customer choice" (Ballou, 1987; Magee et. al, 1985). The fifth dimension points to a model which tends to analyze cross-organizational integration in terms of the technologic perspective. The levels of process integration are classified into four categories including process integration, object integration, data integration and standardization of information exchange figure.

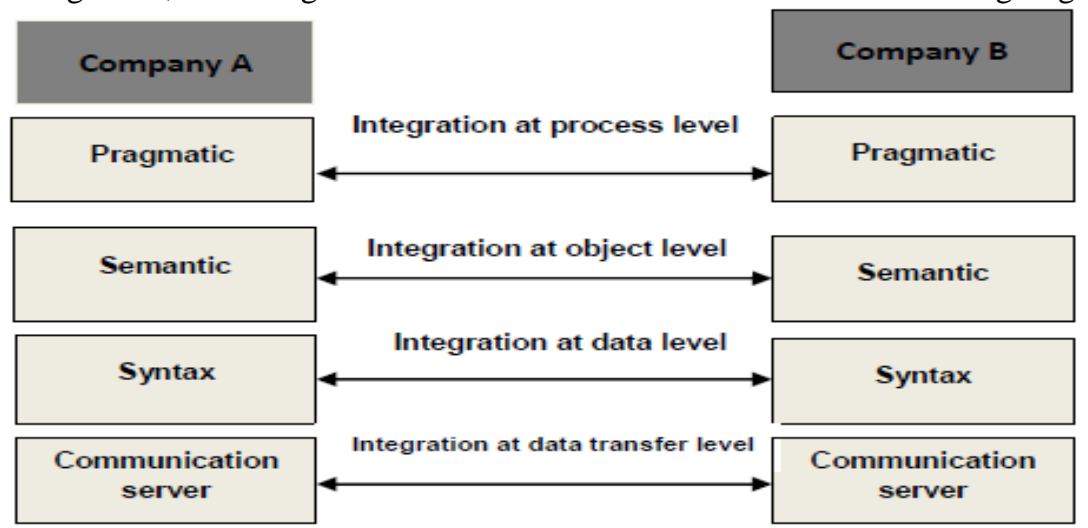

Figure 4.3: levels of cross-organizational integration 
This and other models, developed to describe the dimensions of integration, coordination and cooperation, are all compatible with the above-mentioned model. Hence, it can be used as a comprehensive model for analyzing the dimensions of coordination in the supply chain.

\section{Research Approach}

\section{RESEARCH METHODOLOGY}

The current research will use deductive research approach as the basic methodology of the research is to deduct the results from the available literatures that are available on the impact of Enterprise Resource Management (ERP) on the Supply Chain Management (SCM). The research study will help to draw the empirical results that will contribute in the future studies and also the available literatures on the current genre of the study. The research study will be more focused on the deducing results rather than inducing the new results based upon the assumptions. The research study will also specifically focus on the individual literatures based upon the Enterprise Resource Planning (ERP) and the Supply Chain Management (SCM).

\section{Data Collection}

Since, the research methodology being used for the current research is deductive research and for this reason, secondary sources are used. The research study will use the previous literatures that are available on the current genres of the study. The literature that is based upon the Enterprise Resource Planning (ERP) will be assessed while the literature that is based upon the Supply Chain Management (SCM) will also be assessed. The research study will also assess those literatures that are individually based upon the interactive studies of Enterprise Resource Planning (ERP) and the Supply Chain Management (SCM) is also assessed.

\section{Result Analysis}

The results will be empirically drawn from assessed literatures. The directs results will be empirically drawn where the literatures are directly about the subject matter while the similar results will be drawn from the results of other genres by molding the results towards the studies.

\section{Information Management in achieving Co-operation Mechanism Information Integration}

Integration of the supply chain refers to the internal and external integration in the sense that internal business processes are to be integrated and supra-organizational processes to be incorporated. Integration of the internal chain denotes the assimilation of intra-organizational activities such as purchase, warehousing, material management, transport and production (Croom et. al. (2001). Indeed, the question pertaining to the degree to which these processes are integrated should also address the information systems supporting them. Even if intraorganizational processes are thoroughly integrated, the competitive advantages of an organization may not persist independent of external integration and cooperation with partners. Information integration within an organization takes place through supporting core processes by the same system and database. In fact, this is the method used to realize the implementation of ERP systems, process integration and enterprise information (Puschman\& Alt, 2001).

Information integration in the supply chain is a higher-order sharing of information because while it is likely to share information using any communication device (e.g., telephone, fax, etc.), information integration often denotes systematic methods of information exchange (figure 4.1).

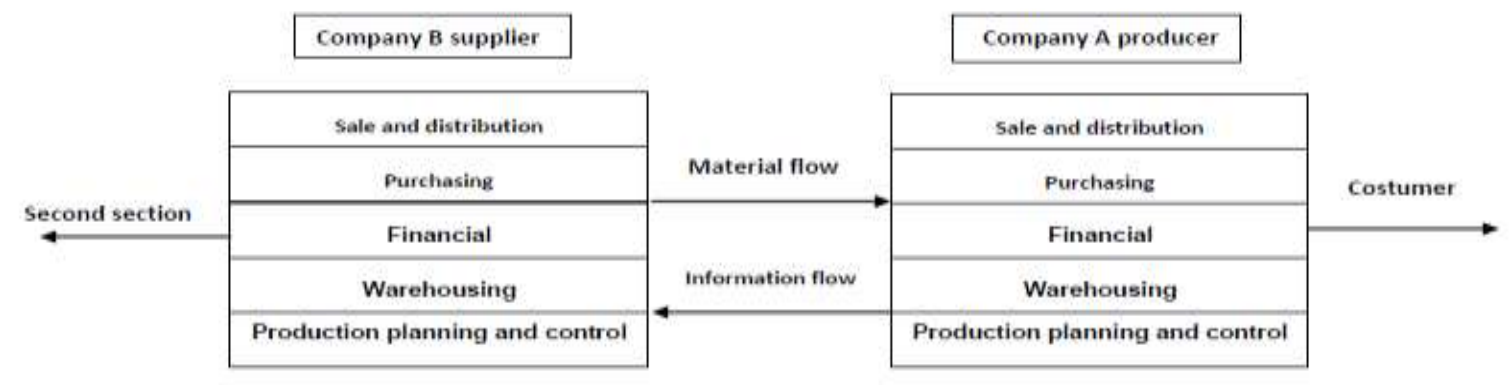

Figure 5.1- Integration of Information between two organizations

Sharing such information as data pertaining to point of sales from retailers or data relating to the quantity of orders in two successive stages in the supply chain may directly influence production planning, delivery and controlling members' supply. The quick developments in information technology such as database management systems, network communication protocols, electronic exchange of data and internet, the flow of accurate and immediate information have been made possible (Zhang et al, 2004).Consequently, sharing information across the supply chain may be regarded as a feedback among the supply chain members if it is supported by information technology. Without such relationship, the down-stream members may receive a delayed feedback 
with some time interval. Under the worst circumstances, the down-stream members would be informed of the quantities and transport schedule only when the merchandise is already arrived. Such a much- too-delayed feedback cannot serve anything in the forecast and calculations. The flow of information reduces the complexity of decision-making and improves the quality of decisions. A well-timed sharing of information through DEI, fax, Email and other information technology media is a solution for providing a supplier and his customers with quick, direct feedback, which helps the company with exploiting dynamic decision-making.This information may include information pertaining to demand, warehouse stock, etc. The range of information may be so vast to include even the information pertaining to the product design (Mourtizis et al, 2004) and quality (Tsung, 2000 ) as well. Figure 5.2 illustrates some types of information. Although, sharing information would enable the other members of the supply chain to better manage their internal processes and to improve their performance indices, such issues as the effects of information exchange on the intra-organizational processes and the formation of supra-organizational processes are not dealt with at this stage; rather, they are covered at the cooperation level. As explained earlier, information integration in terms of technology requires the utilization of information services as well as integration at the data syntax level. In case the two enterprises are using the same information systems, the integration will be inherently realized at this level. To establish such level of integration, the two organizations need to exchange information.

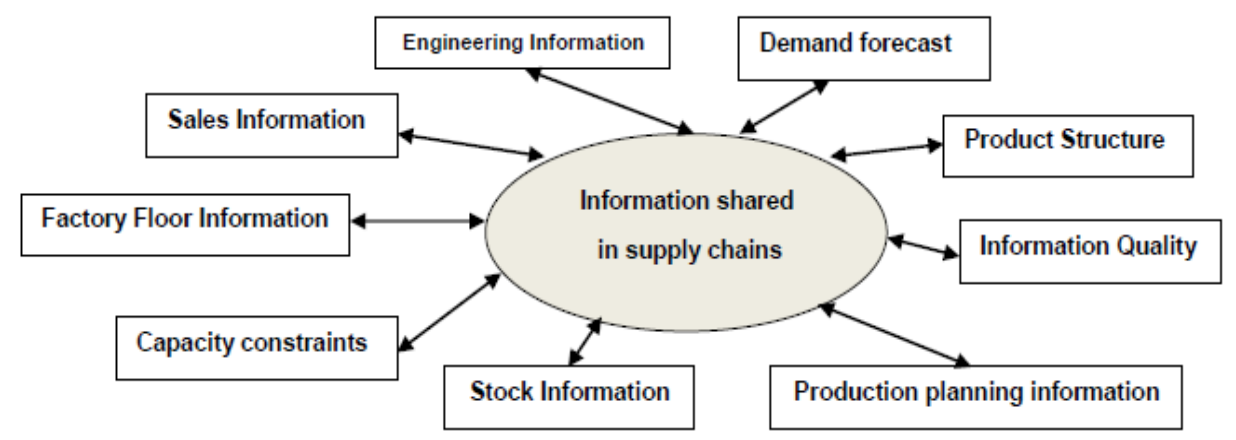

Figure 5.2- sharable information in the supply chain

Studies carried on to investigate the profitability of information exchange in consumption goods industry indicates that such exchange would exert a positive impact on the profitability of the involved enterprises such that as the exchange rate increases, the profitability of the organizations will also increase. Moreover, case studies on computer manufacturing industries suggest information exchange to have an impact on the reduction of expenses (Lee, 2010). Information exchange among the supply chain members with independent ownerships may entail a variety of barriers. Figure 5.3 illustrates major impediments to the information exchange and the role each may play in this process. One major barrier is that traditionally every enterprise with independent ownership may take its own profitability as significant and consequently disregards other member's performance in the chain. In this case, each member in the chain may assume themselves as an independent entity striving to improve not only their bargaining power but also to sell their product to the other members at the highest price; therefore, they refrain from sharing their financial and operational information. Of course, the joint ownership of members in the supply chain would alleviate the resistance to information sharing. However, this is not the only solution to the problem; rather, there have been many studies to examine motivational factors that encourage information sharing. Another major barrier refers to the unavailability of accurate information within the enterprise, which indicates a lack of integrated, efficient information systems (Sinha et al., 1989). A further barrier is the existence of heterogeneous systems in the supply chain whose integration requires high cost and strong cooperation among the members.

Despite the barriers that prevent the information exchange based on information sharing among the supply chain members, this is the first step in creating coordination in the supply chain. Evidently, unless this fundamental factor exists, the other coordinating factors will not be realized. As explained above, the existence of coherent information systems will alleviate many of these problems, though some other barriers depend on the organization policy and culture. 


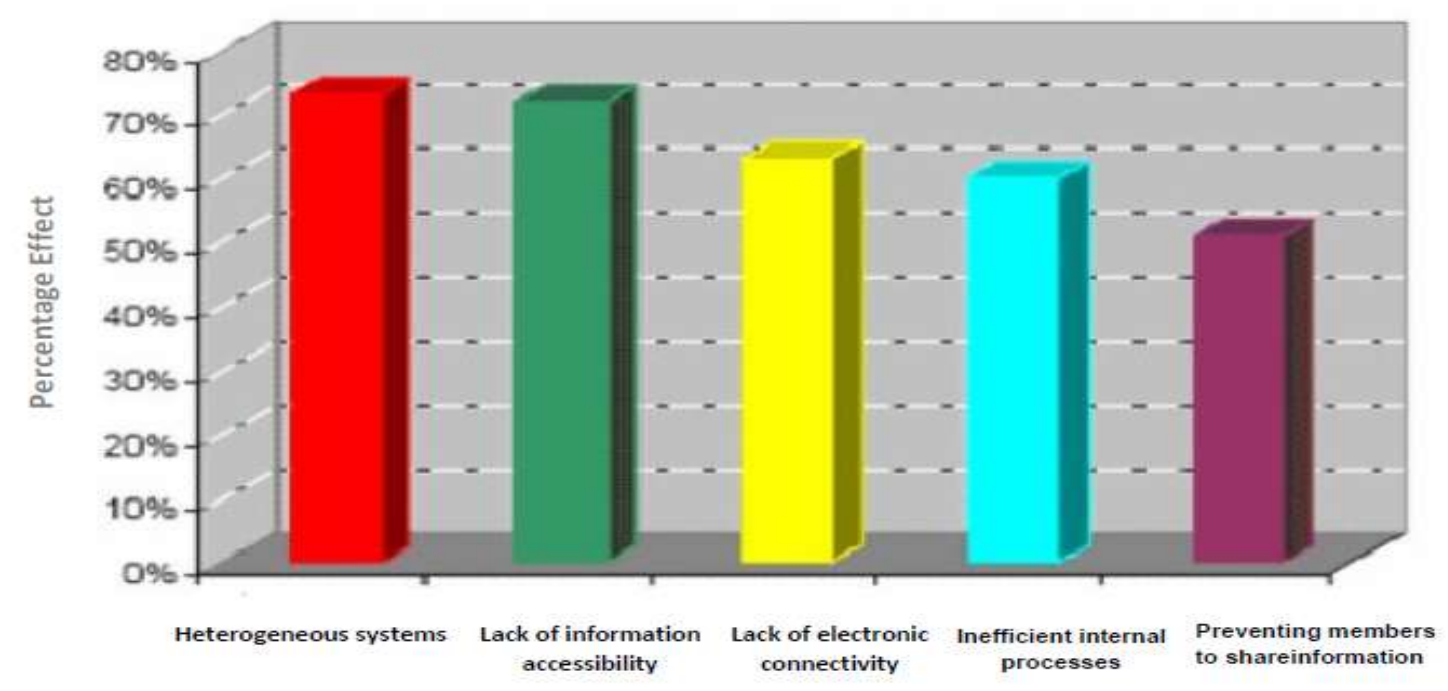

Figure 5.3- information integration barriers

\section{Cooperation mechanisms in the supply chain}

As shown in 5.1, sharing information helps realize the clarity of information in the supply chain. With regard to the model presented, this factor in addition to information integration requires the integration of processes as well. Though, the term cooperation has been given many definitions in the supply chain literature, all these definitions denote both a common goal shared by the supply chain members and the involvement of supply chain members in routine decision-makings like the amount of orders placed, delivery deadline and sales particulars (Judge, 1997). Lack of cooperation and information exchange among members of the supply chain will instigate the bullwhip effect. This phenomenon will be observed due to such reasons as the demand forecast based on manipulated data, unclarity of end-consumers data, orders placed in the form of cargo and price fluctuation. The members' performance is such that each member's order fluctuation toward an upstream member will be higher than an order fluctuation received from a down-stream member.One major goal of cooperation models, to be covered in the following sections, is to alleviate this phenomenon and its causes. These mechanisms, formed in cooperation with adjacent participants to the chain, require not only the exchange of information between down-stream members but also using this information in processes and decisionmakings affected by the information.

As Chandra (2007) puts it, issues pertaining to the supply chain should be determined and also the information pertaining to each member in the supply chain should be shared in order for the supply chain processes to be formed.

\section{Information structure of cooperation mechanisms in the supply chain}

There have been attempts at creating cooperation in the supply chain, which include mechanisms involving adjacent and independent members in the chain such that the members would consider long-term relationships and take each other as significant in their survival. These structures include:

I. Sequential information sharing: in this structure, every member's activity output is the next member's input. Thus, cooperation processes founded on this information structure are connected in a chain-like manner. These types of mechanisms are easier to implement than other mechanisms. Due to the sequential flow of information, each pair of the supply chain members can select their own protocol for the information exchange; therefore, there is no need for a pervasive standard as to the information exchange among the members (Markus and Tanis, 2000).

II. Reciprocal information sharing: this structure bears a more complex structure than the previous one. The reciprocal exchange of information may lead in a higher probability for the information inconsistency; therefore, it is necessary for the corresponding processes to be coordinated and integrated.

III. Hub-and-spoke information sharing: this type of information sharing works based on a central hub which is connected to all members. Internet hubs usually act as a virtual market and help create cross-organizational processes. These information hubs are to store up every member's information and make decisions based on the accumulated information; subsequently, they inform the members of the decisions made (Caldas and Wood, 1998). 


\begin{tabular}{|c|c|c|c|}
\hline Data Exochange & Ordinal & Mutual & Central \\
\hline \multicolumn{4}{|l|}{ Structure } \\
\hline Level of cooperation & $\begin{array}{l}\text { Between adjecent me } \\
\text { mbers, unilateral }\end{array}$ & $\begin{array}{l}\text { Between adjacent } \\
\text { members, Bilatersl }\end{array}$ & Central, Bilateral \\
\hline $\begin{array}{l}\text { Cooperation } \\
\text { mechanism }\end{array}$ & Upward information flow & $\begin{array}{l}\text { Multi-way } \\
\text { information flow }\end{array}$ & Smart hub \\
\hline Technology & EDI, Fax, Tell & EDI, Integrity, work flow & web services \\
\hline Examble & $\begin{array}{l}\text { Traditional } \\
\text { supply chain, 3PL }\end{array}$ & vmat & CFRP \\
\hline
\end{tabular}

Table 5.4- information structure of cooperation mechanisms (Adam and O' Doherty, 2000a).

\section{Classification of cooperation mechanisms based on decision-making}

Examples of cooperation mechanisms, which have demonstrated much practical functions, include vendor managed inventory (VMI), collaborative, planning, forecasting, replenishment (CFRP) and efficient consumer (ECR). These mechanisms may improve such supra-organizational processes as order management, distribution, planning and forecast. The supra-organizational processes pertaining to these performance indices including stock-out, warehouse stock and transport optimization will be improved by these mechanisms. While these mechanisms have different functions in different industries, they are classified into three categories based on the decision-making process in the supply chain (Holweg et al, 2005).

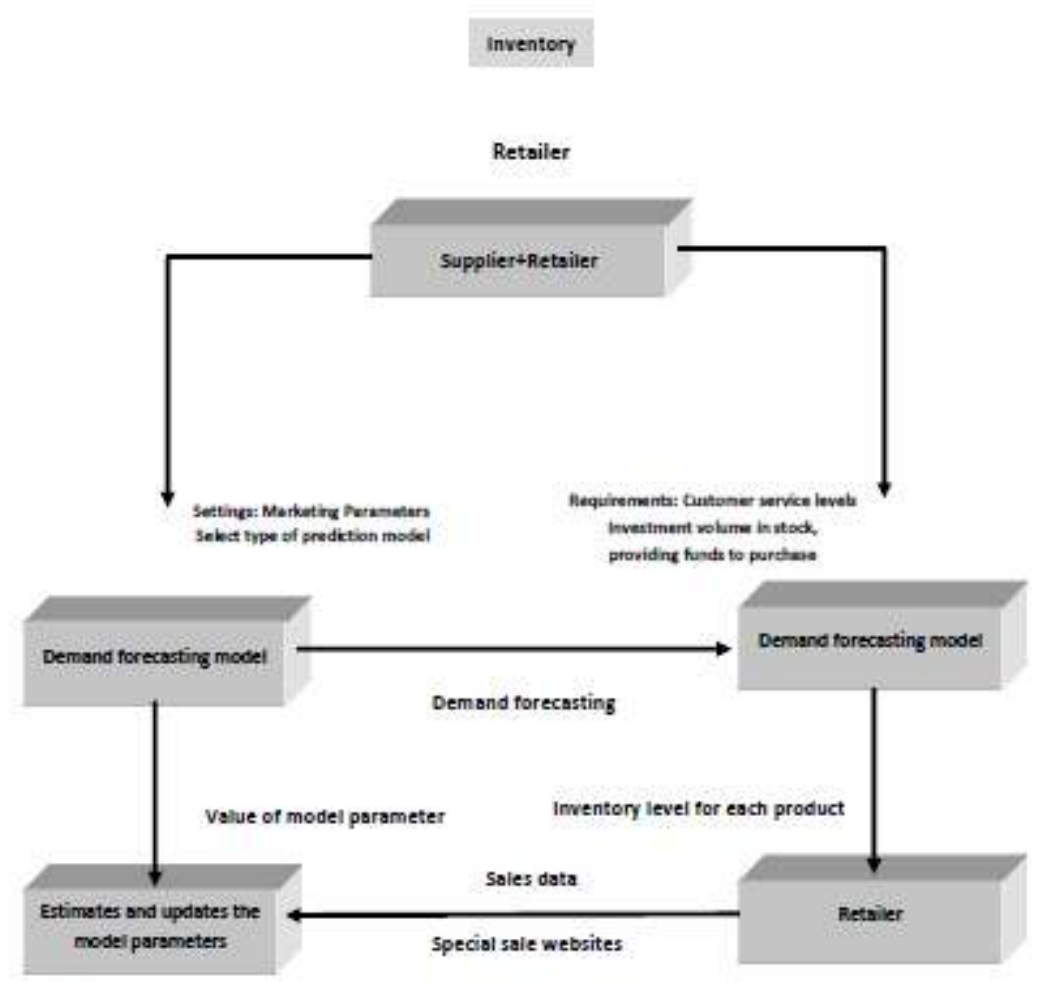

Figure 5.5 - VMI mechanism decision-making model in the retailing industry 


\section{Coordination in the supply chain}

Coordination in the supply chain would be possible through the development of information integration and cooperation mechanisms in the supply chain because that is the only method which produces an overall picture of the supply chain based on which it becomes feasible to optimize a supply chain according to its particular characteristics. At this level of cooperation in the supply chain, i.e., when cooperation and coordination are realized in the supply chain, the underlying structure appropriate for creating mass customization can be implemented in the chain (Kelly et al., 1999). It will be possible to achieve appropriate policies for pricing and discount only if the supply chain information is crystal clear. To achieve coordination among members of a supply chain, the particulars of that chain as well as the polarity of power in the chain should be investigated That is, in case there is a powerful pole in the chain, it will become a pioneer in the implementation of cooperation and integration mechanisms in the supply chain.

\section{ANALYSIS}

The underlying role of ERP in supporting the supply chain management

Having defined and classified cooperation mechanisms in the previous literature studies, we would now explore the role of ERP systems in creating as well as implementing the various co-operative mechanisms. However, before dealing with the supply chain information structure and utilizing ERP system, we will examine how the underlying structure of the supply chain is created. Chandra and Kumar (2006) have classified the supply chain modeling into two topics: decision-making modeling and information structure modeling

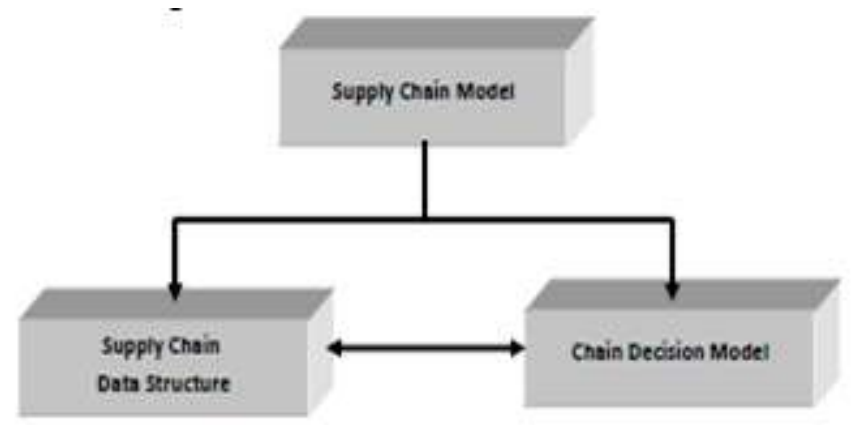

Figure 6.1: Major factors in the supply chain modeling

\section{Major factors in the supply chain modeling}

The information structure fulfills the informational needs of the supply chain and deals with solutions to the problems that the supply chain decision-making model may entail. The supply chain involves an information structure in which each member of the chain holds three major processes of supply, production and distribution. These three major corporate processes are integrated by three major logistic modules of ERP system. These characteristics data, (in Figure 6.2) integrate and managed by different process of modules of material management (MM), production planning (PP) and sales and distribution (SD).

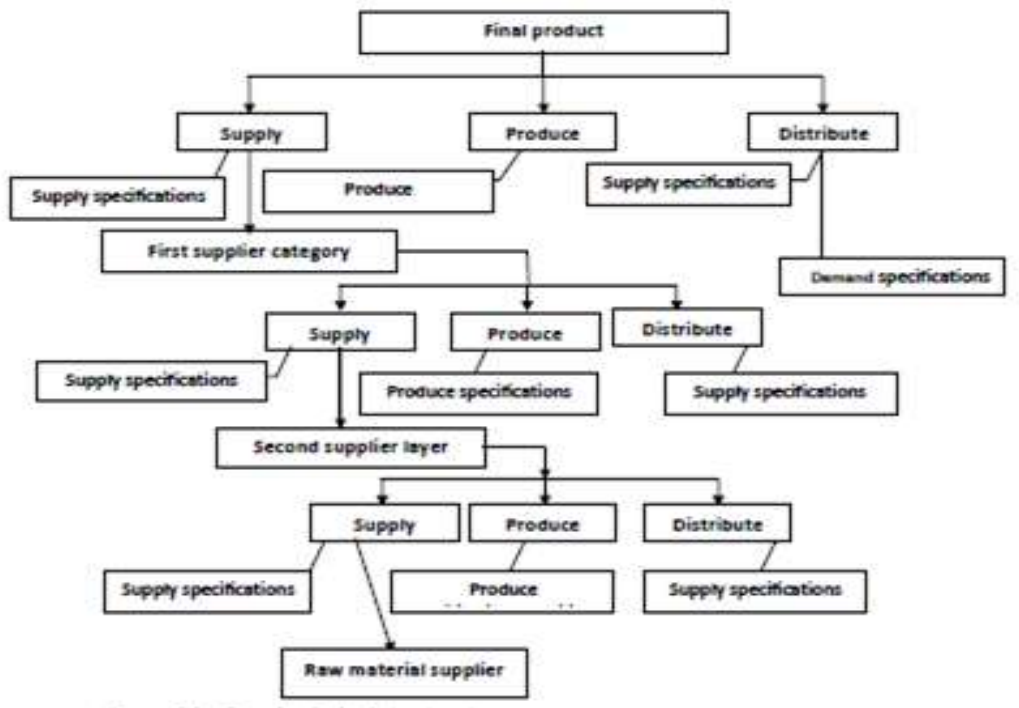

Figure6.2: Supply chain data structure 


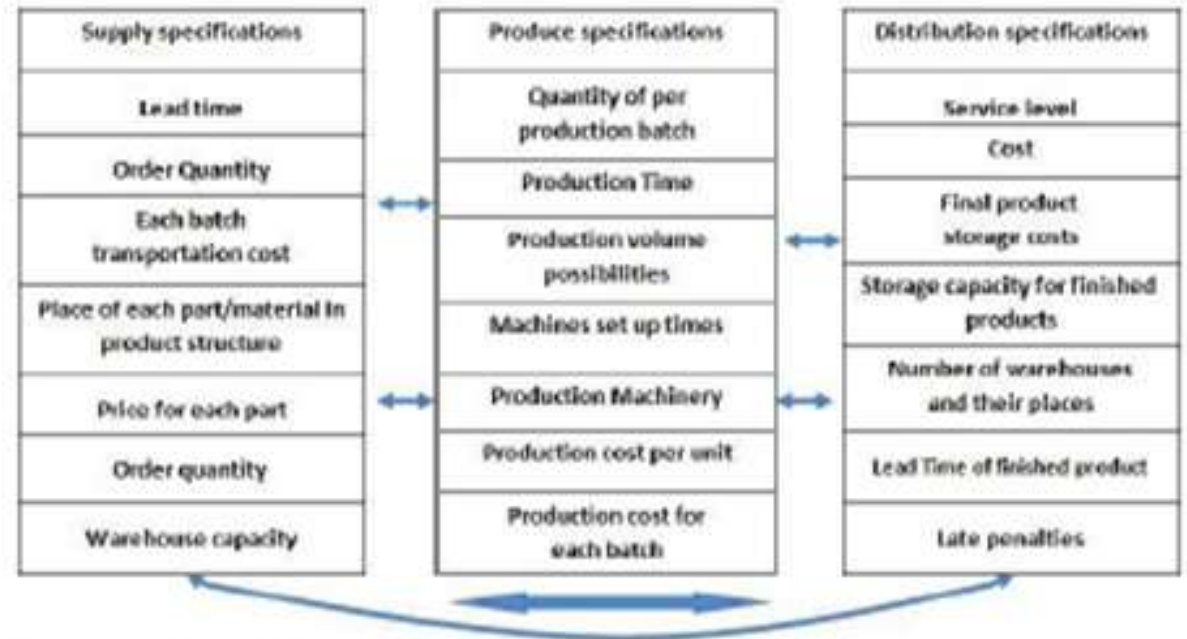

Figure6.3: Characteristics of information supply chain structure

\section{Integration of supra-organizational processes}

One of the most fundamental ERP aims is to integrate the organizational processes, but the evolutionary tendency of the process integration has driven it towards supra-organizational process integration and the creation of collaborative business process (figure 6.4) so that new requirements will be imposed upon IT systems supporting these processes.

Cooperation processes or collaborative business scenario joins up an inclusive network of the raw material suppliers to the customers. Despite processes that used only to consider intra-enterprise value chain, collaborative business processes or C-business tends to integrate all the steps that provide value for the customer across the supply chain (Zang et al, 2004). Collaborative business processes have their own implications in different industries at different levels from the stock control to planning the product development (Liu \& Kumar, 2003). The supply chain information systems supporting these processes hold an information structure which includes such components as the chain structure, product structure, demand forecast and production stock management (Chandra, 2005). These processes can be explored from various perspectives including the conceptual planning of collaborative business processes, the underlying technology for integration, modeling and

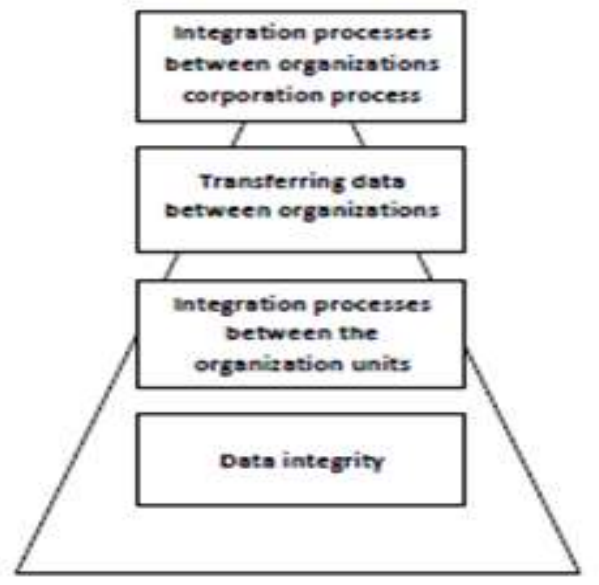

Figure 6.4: Evaluation of process integration by ERP

verification, and flexibility (Kelly et al., 1999). These processes are managed at three layers including Cbusiness strategy, process engineering and process implementation. At the strategy layer, processes are demonstrated by higher-order modules. The information presented at this level will address all the organizations involved in the process. The process engineering layer elucidates the role each organization would play in the process implementation. It also demonstrates the output information where it is due to be issued. The implementation layer refers to the information technologies that help realize the integration of processes and data (Zang et al, 2004). 
The role of ERP in creating cooperation mechanisms

With regard to the model introduced in the previous section, we shall now examine the role of ERP systems at different levels of cooperation including integration, cooperation and coordination. As mentioned earlier, integrating the information is the first step in creating cooperation in the supply chain. Creating integration or the systematic exchange of information develops at two levels of processes and data. If the supply chain includes some ERP systems, there should be an intermediate ERP system to connect various levels (figure 6.5). The intermediate system is responsible for receiving the information extracted from ERP databases established at different levelsin the supply chain and subsequently converting it into formats that can be received by other ERP systems as well as transferring the information to ERP databases. The technology of this intermediate software uses such formats as EDI, HTML and XML to transfer the data (Ball et al, 2002).

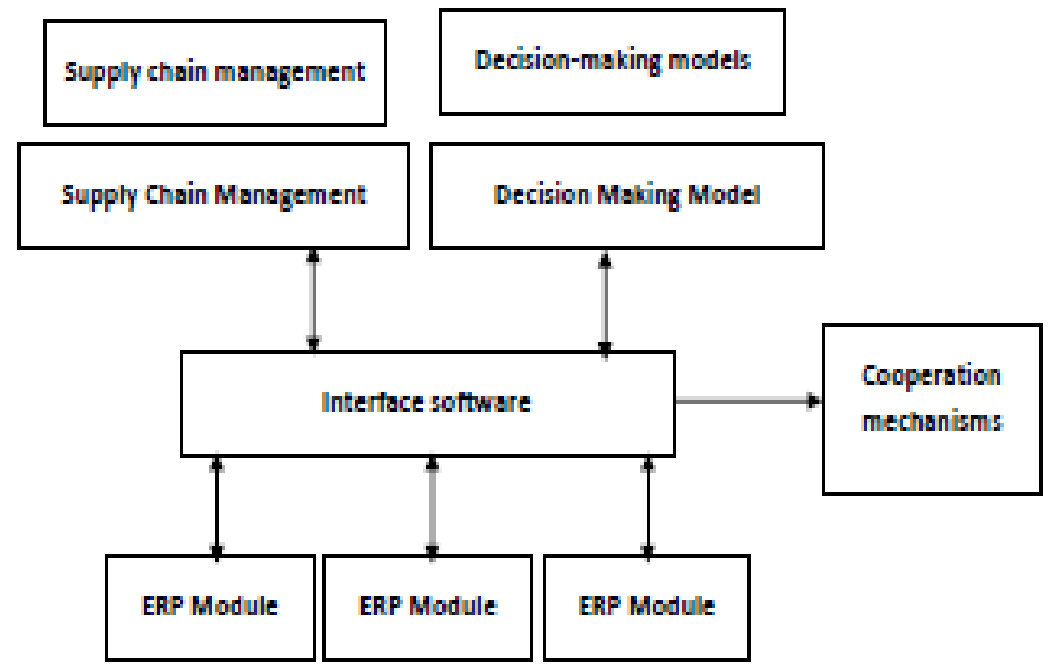

Figure 6.5 - The role of ERP in creating the supply chain systems

To exchange information at the data level, the data resources distributed across the supply chain need to be connected. Exchange at the data level can take the form of receiving information from an ERP database in order to update another ERP database- the information field of the data should be defined in either of the databases (Ball et al., 2002). However, if the information exchange is at the process level in the sense that processes in the two organizations should be interrelated, the functional routine of some of the organizational processes should be integrated as well- (Themistocleous et al., 2002). An example of this can be a scenario in which the information pertaining to the vendor's warehouse is transferred to the supplier. Subsequently, the information will be interpreted by the supplier's system and in case the warehouse stock level is lower than the permissible level, the supplier will be informed.

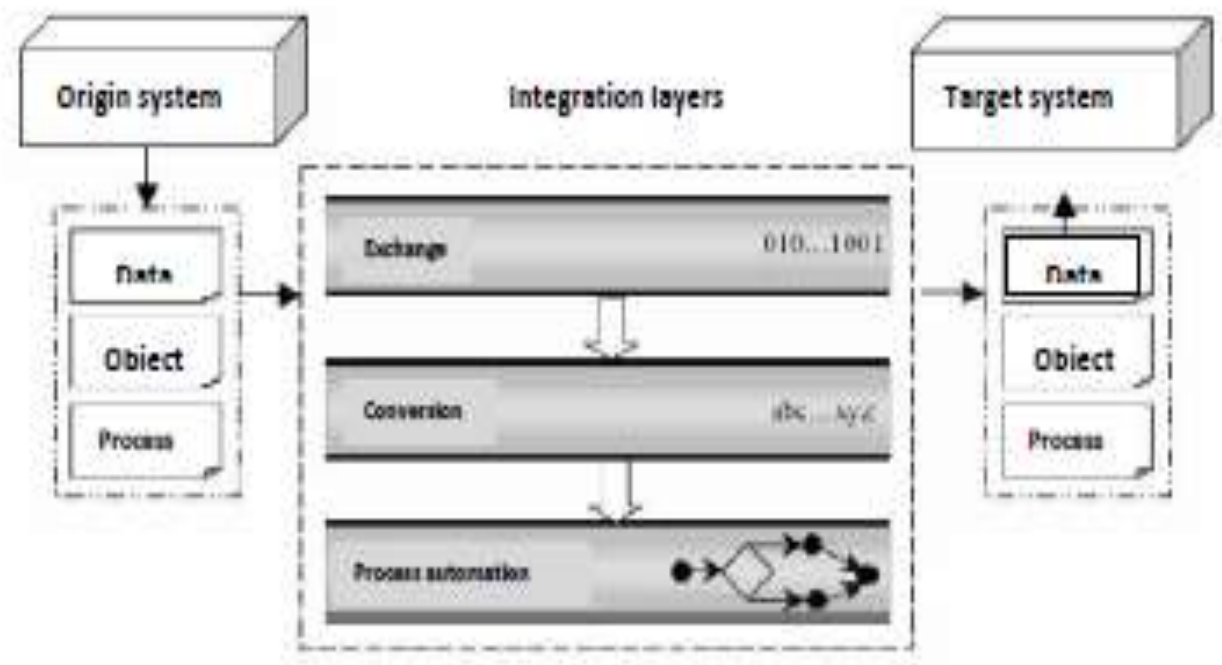

Figure 6.6 - Layers of cross-enterprise business process integration 


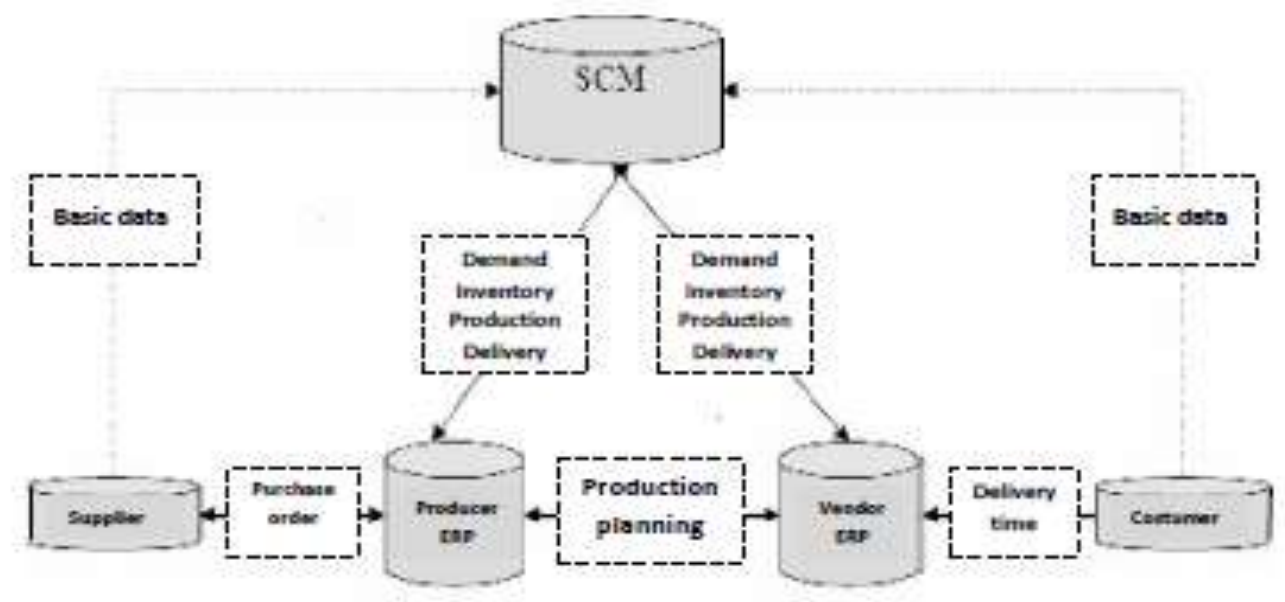

Figure6.7 -ERP role in the implementation of supply chain process

As mentioned earlier, integration at the process level can be created in the intermediate software. Another example to be acknowledged is the process of planning the supply chain. The process, which should be implemented at different levels in the supply chain, include such steps as: the accumulated pre-demand across the supply chain, distributed requirement planning across the chain ranks, and Master Production Plan (MPS) for every manufacturing member. Then each production unit should be implemented through using the input of ERP master production plan. The integrated processes will be implemented at different levels of the chain respectively (figure, 6.7).

\section{Findings and Discussion (Output)}

During the various study through the literatures, it is evident that manufacturing companies have undergone many evolutionary changes. The concept of SCM has helped companies to compete flexibly. The importance of a long term long lasting relationship has been enlightened in this work. Co-ordination, cooperation and integration will improve profitability not only to the manufacturer but also to the supplier. With the emergence of technology new developed software's and architectures have been available for managing various operational levels in a supply chain management and one among these technologies is the widely used Enterprise Resource Planning. Order management has received wide recognition from researchers and practitioners. The timeliness and accuracy of order transmission and its fulfillment have always been a major goal of supply chain management. We have tried to propose methods to achieve better order management in SC systems. There is a complex situation in order processing due to the complexity of members in supply chain. This makes interaction complex and also placing an order across the complex system becomes order. Cost is an important element in the supply chain and therefore playing down with the cost is very essential.The impact of ERP system is always results from the case studies, interviews and industry surveys. Companies report growth in the performance in several areas as a result of ERP implementation. The impact of ERP implementation always branch out into four categories.

I. information flow across sub - units, standardization and integration facilitates communication and better coordination.

II. Enabling centralization of administrative activities such as accounts and payroll.

III.Reduce information system maintenance cost and increase the ability to deploy new functionality.

IV. ERP helps in moving a firm from inefficient business process into accepted practice process. (Galbraith, 1974).

These above literatures states that ERP systems has potential benefits on the organization on successful implementation.

Cooperation processes or collaborative business scenario joins up an inclusive network of the raw material suppliers to the customers. Despite processes that used only to consider intra-

enterprise value chain, collaborative business processes or C-business tends to integrate all the steps that provide value for the customer across the supply chain (Zang et al, 2004). Collaborative business processes have their own implications in different industries at different levels from the stock control to planning the product development (Liu \& Kumar, 2003). The supply chain information systems supporting these processes hold an information structure which includes such components as the chain structure, product structure, demand forecast and production stock management (Chandra, 2005). These processes can be explored from various perspectives 
including the conceptual planning of collaborative business processes, the underlying technology for integration, modeling and verification, and flexibility (Kelly et al., 1999). These processes are managed at three layers including C-business strategy, process engineering and process implementation. At the strategy layer, processes are demonstrated by higher-order modules. The information presented at this level will address all the organizations involved in the process. The process engineering layer elucidates the role each organization would play in the process implementation. It also demonstrates the output information where it is due to be issued. The implementation layer refers to the information technologies that help realize the integration of processes and data (Zang et al, 2004).

\section{Research areas on ERP}

There are two main research orientations in these studies which include: first, how to implement ERP system in a corporation and, second, what are the advantages of this system in resolving a variety of problems an organization might encounter.

The first area, on which most of the studies have already focused, comprises studies on the fund, timing, economy and success of the implementation of ERP. On the contrary, there have been few studies to address the functions of ERP in strategic and operational levels. Studies on ERP are often classified into two categories: studies on the concept of ERP and studies on the system of ERP. Conceptual studies on ERP have concentrated on the potential effects that ERP might have on the organization, while studies with systemic orientations have presumed ERP as a tool for creating a particular output (Cumbie et al., 2005). Table 6.1 illustrates some of the research topics in each one of these areas.

Table 1. : Two main topics ERP studies

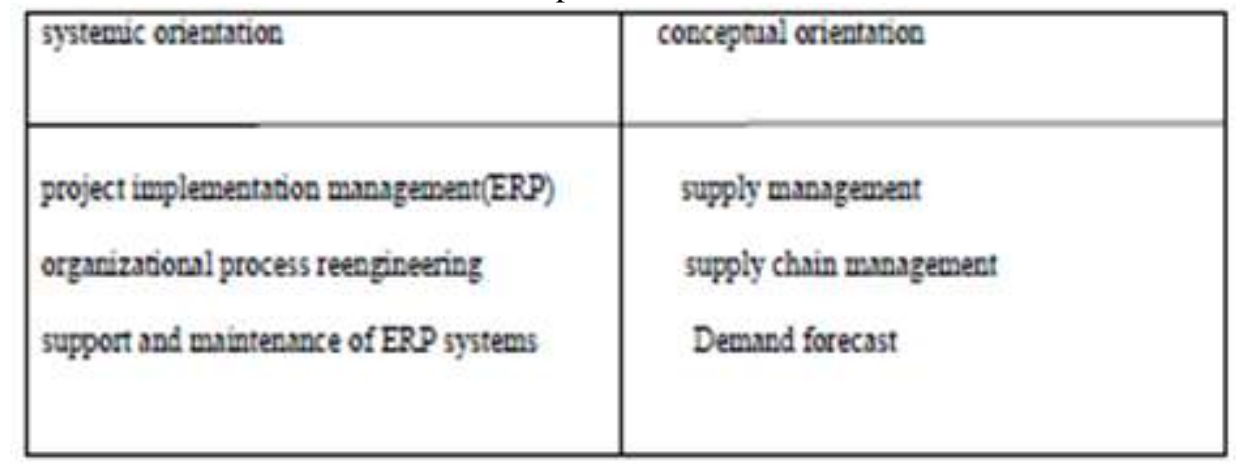

Still, researchers have proposed different classifications for the studies carried on ERP. Such researchers as Genoulaz et al. (2005) have placed the studies carried on ERP during 2003 and 2004 into five distinct categories. The first category goes for the case studies that investigate the implementation of ERP as well as issues pertaining to it such as socio-cultural factors in the implementation of ERP, correspondence between ERP and business processes, ERP software and ERP for supply chain management. The second category involves studies that examine the organization's profitability and performance after the implementation of ERP (Subramoniam et al., 2008). Also, these studies seek to explore the effects of the implementation of ERP in gaining competitive advantage. An example of such studies is the works by Nikolaou and Bhattacharya (2005) in which the long-term effects of the implementation of ERP have been explored on the organizations fiscal performance and profitability. The third category includes studies that address the effects of the implementation of ERP on the organizational management (including such factors as managerial levels and organizational culture). An example of this is Boersma and Kingma's study on the implementation of ERP in multinational corporations. Also studies by Disha and Merits (2002), which examine control and integration after the implementation of ERP, fall within this same category. The fourth category involves studies concentrating on ERP tools which encompass such issues as: system structure, programming language and information modeling, establishing logical relationship among ERP database tables and customizing this system with actual demands and conditions of business. 


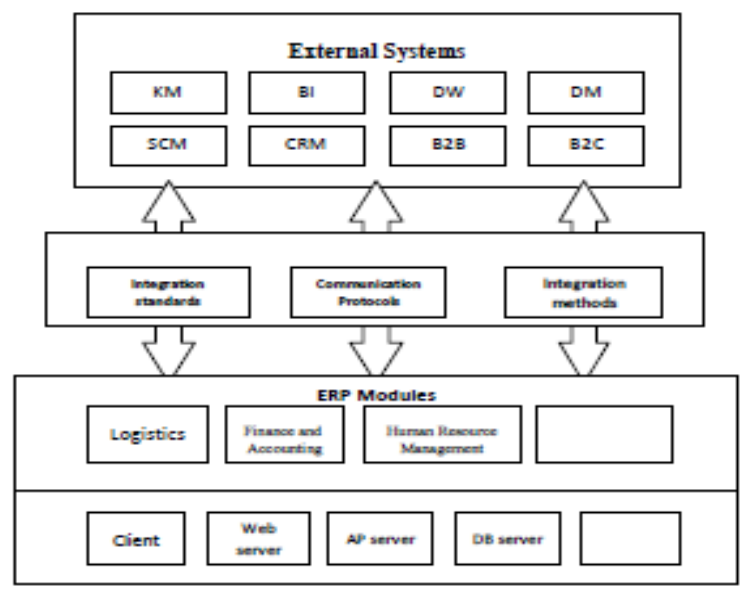

Figure6.8 : ERP connection with other enterprise systems

Studies that fall into the fifth category deal with the importance of ERP as a foundation for other enterprise systems (e.g., CSM and CRM) (Glaser and Strauss, 1967; Strauss and Corbin, 1994;Webster and Watson, 2002). ERP would integrate business processes within an organization. Since, even with the presence of other enterprise systems such as SCM, CRM and SRM, many a decision along the supply chain may not be integrated; therefore, there ought to be studies to investigate the integration of ERP with other information technologies (e.g., APS and MES). This way the decision-making process between various system modules (e.g., sales and production planning) may be integrated (Chen, 2000). In this connection, there have been many studies to investigate the effects of ERP on improving cooperation and coordination in the supply chain, which deal with the sharing of information in the supply chain as well as its impacts on the supply chain performance (Kelle\&Akbulut, 2005). The topic under investigation in this dissertation falls within this same line of research.

\section{Business Value of Information Technology}

There are extensive sources of information's available which supports impact of information technology. Investment in information technology has resulted in significant effect on productive levels, growth and also the value of business organization. There are also other works which have proved that there are also positive results on internal performance such as inventory turnover (Barua, Kriebel and Mukhopadhyay, 1995). All these researches suggests that there are positive benefits from the implementation of IT systems with successful ERP deployment, many little have pointed out the statistical models and reports that favors the advantages.

Over the last few decades, companies have paid a considerable attention to the methods of Manufacturing Planning and Control Systems (MPCS). Management responsibilities concerning the concept of MPCS include:

I. Determining the requirements of a reliable capacity to fulfill market demands

II. Creating activities concerning scheduled production, manpower and machinery coordinated in an appropriate function.

III. Tracking materials and customer orders will support machinery planning and other resources (Neuman, 1997).

MRP is a system which is likely to support the concept of MPCS. This system, first developed in the 1970 s, serves as a precision tool for the accurate planning of materials in manufacturing and assembly lines. In the same direction, in the 1980s, alternative MRPII systems were introduced which emphasized the optimization of production in regard to production resources (Shehab et al. (2004)). The first ERP system was introduced by SAP Company during the late 1980s. The system had the capability to integrate the overall business processes within a corporation. ERP denotes a system whose modules integrate the whole activities within an organization such as planning, production, sales, marketing, distribution and accounting. It utilizes the same database and function in the whole organization. Technically speaking, EPR systems are generally planned based on client/server technology which comprises three layers of database layer, application layer and graphical user interface (GUI)- (Kalus\&Roseman, 2000). During the 1990s, suppliers of these systems incorporated new modules with new capabilities into ERP. These newly-added modules include advanced planning and scheduling (APS), customer relationship management (CRM) and supply chain management (SCM). Each one of these modules or their integrated combination are also called enterprise system.

Each process has so many specifications but major characteristics for profile of each process from the perspective of the supply chain are shown above. ( Rahul V. Altekar 2007). NET, J2EE), databases (e.g., Oracle and MS SQL) and decision support systems (DSS) employed in advanced ERP systems are not necessarily 
developed by ERP providers themselves; rather, they are newly-established technologies integrated with enterprise systems by ERP-developer companies, and thus these systems have gained a higher significance. This theory has helped develop a second generation of Enterprise Resource Planning (ERP II). In addition to utilizing the underlying structures of ERP system, these systems also incorporate two more layers of analysis and Portal.

\section{ERP and Decision making}

During recent decades, enterprises spend billions of dollars to implement and use of ERP, indentify implementation goals of ERP and And utilization planning for ERP is one of the critical factors for successful implementation, such as standardization of business processes and integrating operations with the data are primary goals of ERP (Botta-Genoulaz et al. (2005)) .

Studies show that ERP Alone has a positive impact of various decisions, Kohli and Gupta consider ERP's benefits In operational decision making in the field of design processes, programs planning and production operations, respectively, warehouse management, quality management and human resource management.

As mentioned earlier in this chapter, ERP helps integrate the internal processes within an organization; hence, it lacks a chain management perspective. Still, this integration provides companies with an instrument for the integration and optimization of the supply chain. To successfully integrate the supply chain, companies need to exchange a great deal of programming and operational information so that through facilitating the immediate accessibility of members to such information as production planning, delivery of materials and point of sales, the supplier-customer relationship will be improved. ERP structure may not support business models across the supply chain. However, taking a macro-level perspective on the supply chain and using such technologies as internet and Extended Mark Up Language (XML), companies may be capable of distributing the processes throughout the supply chain(Esteves and Pastor, 2001). A critical factor in supply chain management is to utilize ERP systems in integrating the information pertaining to the chain members. In short an ERP system provides an organization with the following advantages.

$\square \square$ Reduce operational costs and improve efficiency

- Gain better visibility of transactions across the enterprise

- Make better business decisions

- Deliver the right product at the right time

- Keep customer promises

- Adopt manufacturing best practices, including lean

In many instances, researchers have taken ERP as an underlying structure for other enterprise systems, particularly the supply chain management. In some instances, companies have drawn on the data extracted by Extraction, Transformation and Loading technique (ETL) from ERP databases to model and/or simulate the supply chain networks and make strategic decisions. There have been studies to investigate the utilization of underlying informational ERP systems in implementing supply chain managements based on Supply-Chain Operations Reference (SCOR), which suggest that it is unavoidable to use the information pertaining to the supply chain management, extraction and the concentrated information in enterprise databases because the information is supra-organizational (Chopra, 2007; Ball, 2002)

\section{Research topics on decision support systems can be classified into three categories:}

The first category involves studies that concentrate on information retrieval. At first, the databases of decision support systems (DSS) were unstructured files, but they were displaced by logical databases then. There are new storage technologies such as data warehousing, online analytical processing (OLAP) and report generator, which are used for retrieving information (Hess \& Wells, 2002).

The second category encompass studies that seek to investigate the development of decision-making models including optimization models as well as statistical and analytical tools which utilize such programs as Visual Basic for modeling and defining decision-making process.

The third category includes studies that deal with the knowledge concerning decision-making, introduction and assisting the decision-maker to select the potential options for decision-making and recognizing the outcomes of each one of these option(Esteves and Bohorquez 2007). Some of the techniques, used for problem-solving in decision support systems and investigated at the relevant knowledge levels, include Fuzzy Logic, genetic algorithm, neural networks and linear optimization (Worley et al, 2002).

\section{CONCLUSION AND RECOMMENDATIONS}

In this library study, we studied enterprise resource planning (ERP), supply chain management system and decision-making systems. We recurrently pointed out in the review of literature that how ERP can affect the supply chain management. The previous findings suggest that this system has already solved some of the supply chain problems but not others. Some studies have shown that ERP systems play an underlying role in other organizational systems. In this study, we sought to investigate how ERP systems can be used to create the underlying information structure of the supply chain. This underlying structure can be considered as the core 
transactional layer of other systems. The transactional layer has been created by linking ERP systems. It is possible to solve the supra-organizational problems of the chain via processing transactional information. Therefore, the analytical layer, which supports decision-making processes and supra-organizational issues, can only be created via an information structure or the transactional layer. In other words ERP is not enough to solve all the problems of the supply chain; however, there are some considerations that make ERP a prerequisite for analyzing the supply chain issues and organizational decision-making, including: sharing vast information in the supply chain processes, the capacity to absorb this information in the organization and using crossorganizational information in addition to intra-organizational information in the chain processes. In short ERP is a system which helps commercial areas like finance, logistics, sales, production and distribution and etc which are inter-related to each other so that if an activity is registered at one place it reflects immediately at all other places. This was studied in modeling the supply chain which involves the information structure model and decision-making model. In other words, the analytical layer should be created considering the enterprise strategic and tactical issues and their role in the supply chain. In co-ordinance with its advantages ERP also has some major disadvantages which are over shadowed by its advantages. According to the studies of Sunil.C and Peter.M it is clear that ERP focuses on production level and therefore they have a weak analyzation. So it becomes a necessary to have highly skilled professionals to use the software in the planning level. Also another disadvantage is that ERP systems are so expensive and complex and therefore it becomes harder to implement on different systems. Therefore the major requirement of an ERP system is that it has to fit with all other information systems and should be flexible and easy to change with the change of processes and tools of any layer of a system. It needs re-engineering in all the processes and tools in a commerce part and this as per our findings has been the biggest disadvantage of ERP systems. According to our findings the successful integration and operation of ERP systems with other systems depends purely on skilled operators and workers.

The major conclusion that we have arrived from our findings is that we should not much help from ERP on supporting supply chain management in extended enterprises. It was surprising that ERP has become a standard though having a major advantage. After the installation of ERP into an organization a process orientation takes place which will act as a back bone though within a single organizations business areas and supports supply chain management. But ERP systems are not compactable to support SCM across multiple enterprises and therefore IT solutions are required. The emergence of IT solutions has encouraged the implementation of ERP across its boundaries. Emergence of internet and communication systems will help interfacing the individual ERP implementations. Thus according to our findings ERP systems in its current state have a modest role to play in obtaining supply chain integration and management. With the major development in the field of communication and IT solutions we can expect a time shift where many solutions could be available for better interfacing of ERP systems and in turn which can help in achieving good supply chain management.

The major advantage of an ERP system is that it is integrated and centralized. An ERP system offers the decision makers the means of enhancing the knowledge about the process which in turn helps to make reliable decisions more rapidly and as well collecting sources to support their decisions. It also helps managers to handle more larger and complex problems. As per our findings from ERP helps to improve the reliability of decision by mutual participation of the participants, improves co-ordination of tasks which makes inter-related decision making easier. As a result it improves the satisfaction of decision process across the participants.

Research directions. Rescheduling research needs to proceed from in-depth studies of

manufacturers with rescheduling problems. This will allow investigators to identify important issues, validate assumptions, and illustrate insights. More research is needed to compare the performance of manufacturing systems under rescheduling policies to their performance under dynamic scheduling (such as dispatching rules). This will yield additional insight into the advantages and disadvantages of rescheduling in different problem settings. This study could be done by examining analytical models (for those systems where such models exist or can be constructed) or conducting simulation studies (for more complex systems). Although there have been some studies, a comprehensive campaign is still needed. Rescheduling provides a systems view of manufacturing that includes not only material flow and resource availability but also order release and control systems. This perspective will be useful for a wide variety of manufacturing system control problems and should lead to developments in the design and optimization of manufacturing planning and control systems. It will bring closer the vision of a

comprehensive set of models that can describe the complete set of dynamics within a manufacturing system.

\section{Future studies}

This study can function as a foundation for future studies which concentrate on the two areas of crossorganizational decision-making modeling and integration of analytical systems with ERP system. As to the integration of systems, developing the relationship between ERP systems and analytical systems such as decision-making systems provide contexts for the application of this research. On the other hand, developing the supply chain decision-making models categorized based on Supply-Chain Operations Reference (SCOR) may 
be another path for future studies. The performance indices of supply chain can always be improved by the development of decision-making and optimization models with more realistic assumptions. An in-depth research is needed to fill the gap to develop ERP systems to support multiple enterprises.

\section{ACKNOWLEDGEMENTS}

First of all I would like to express my deepest gratitude and sincere thanks to Chairman (Dr. B.S. Goel) and Director (Dr. Sandeep Kumar Singh) of Aryan Institute of Technology, Jindal Nagar, Ghaziabad (UP)-INDIA for valuable suggestions and Motivation to this Efforts for research works on Manufacturing System Performance Improved through Enterprise Resource Planning in Supply Chain Management in Shop Floor and Case Study. They allow to me and provide their valuable time and keep interest in my research work. His intellectual advice has helping me in every step of my research work. I express my sincere thanks to our beloved In the last, I also wishes to thank the students, colleagues, and industrial collaborators who have contributed many valuable insights about the nature of production scheduling, ERP and SCM

\section{REFERENCES}

[1] Arnold, J. R. T., \& Chapman, S. N. (2004). Introduction to materials management (5th ed.). Delhi: Pearson Education, Inc.

[2] Ballou, R.H. (2004). Business logistics/ supply chain management: planning, organizing, \& controlling the supply chain (4th ed.). New Jersey: Prentice-Hall, Pearson Education International.

[3] Bavarsad, B., Rahimi, F., \& Norozy, P., (2013). Determinants and Consequences of Implementation Enterprise Resource Planning System on Financial performance. Institute of Interdisciplinary Business Research

[4] Eckert, S. G., (2007). Inventory management and its effects on customer satisfaction: A case of Kenyan Ferry services. Journal of Business and Public Policy (ISSN: 1936-9794) Vol.1, No. 3

[5] Gaines, C., Hoover, D., Foxx, W., Matuszek, T., \& Morrison, R., (2011). Information systems as a strategic partner in organizational performance. Journal of Management and Marketing Research

[6] Gorla, N., Somers, T.M., \& Wong, B., (2010). Organizational impact of system quality, information quality, and service quality. Journal of Strategic Information Systems, 19 (2010) 207-228

[7] Haghighat, F., (2008). The impact of information technology on coordination mechanisms of supply chain. ( $\odot$ IDOSI Publications, World Applied Sciences Journal 3 (Supple 2): 74-81, 2008, ISSN 18184952

[8] Health Action International Africa, (2007). Medicine prices in Uganda. World Health Organization regional office for Africa: Brazzaville, Republic of Congo.

[9] Hendricks, K.B., Singhal, V.R., \& Stratman, J.K., (2005). The impact of enterprise systems on corporate performance: A study of ERP, SCM \& CRM system implementations. The University of Western Ontario London: Ontario, N6A-3K7.

[10] Jalal, A., (2001). Enterprise resource planning: An empirical study of its impact on job performance. Volume 6, Number 1, June 2011

[11] Achabal,D., Mcintyre,S., Smith,S., Kalyanam,K., 3A decision support system for vendor managed inventory4 , Journal of Retailing New York University, Volume 76, 2000

[12] Adam, F. and O'Doherty, P., 2000a, "Lessons from Enterprise Resource Planning Implementations in Ireland -Towards Smaller and Shorter ERP projects", Journal of Information Technology, Forthcoming Special issue on ERP, December 2000

[13] Ballou, R. H., Gilbert, S. M. , Mukherjee, A. (2000), New managerial challenges from supply chainopportunities, Industrial Marketing Management, Vol. 29, pp. 7-18

[14] Barua, A., Kriebel, C., and Mukhopadhyay, T. Information technology and business value: An analytic and empirical investigation. Information SystemsResearch 7 (4), 409-428, 1995.

[15] Bendoly,E., Schoenherr,T., "ERP system and implementation onprocessbenefits Implications for B r B eprocurement", InternationalJournal of Operations \& Production Management, Volume25, Number 4, 2006

[16] Blackhurst, J, J. 2002. _A Network Based Methodology to Model Supply Chain System‘. Thesis, (PhD). University of Iowa.

[17] Boersma,K., Kingma,S., "Developing a cultural perspective on ERP”,Business Process Management journal,Vol .11, No .2, 2007

[18] Botta-Genoulaz, V., Millet, P.A. and Grabot, B. (2005), "A survey on the recent research literature on ERP systems", Computers in Industry, Vol. 56 No. 6, pp. 510-22

[19] Botta-Genoulaz,V., Millet,P., Grabot,B., 3A survey on the recent research literature on ERP systems4, Computers in Industry, Vol .56, 2005 
[20] Burca,S., Fynes,B., Marshall,D., "Strategic technology adoption :extending ERP across the supply chain", The Journal of Enterprise information Management, Vol.18No 40, 2006

[21] Caldas, M. and Wood, T., 1998, "How Consultants Can Help Organizations Survive the ERP Frenzy",

[22] Capar,I., Ulengin,F., Reisma,A.,(2003 )3A Taxonomy for Supply Chain Management Literature", A paper presented at the World Conference on Transport Research (WCTRS52

[23] Chandra,Ch., Grabis,J "Problem taxonomy :a step towards effective information sharing in supply chain management", International Journal of Production Research,Vol .45, No .11 2008

[24] Chang, Y. and Makatsoris, H. 2001. _Supply Chain Modelling Using Simulation‘. Institute for Manufacturing, University of Cambridge, 2 (1): 24-30.

[25] Christopher, M. and Jüttner, U. (2000): Supply Chainrelationships: Making the Transition to CloserIntegration; International Journal of Logistics:Research and Applications; Vol. 3, No. 1, pp. 5-23

[26] Ciborra, C., 1992, "From Thinking to Tinkering: the Grassroots of Strategic Information Systems", Proceedingsof the 1992 ICIS conference, p.283-291.

[27] Croom, S., Romano, P. and Giannakis, M. (2000),Supply chain management: an analytical

[28] framework for critical literature review, International Journal of Purchasing \& SupplyManagement, Vol. 6, pp. 67-83

[29] Cumbie, B., Jourdan, Z., Peachy, T., Dugo, T.M. and Craighead, C.W. (2005), "Enterprise resourceplanning research: where are we now and where should we go from here?", Journal of

[30] Information Technology Theory and Application, Vol. 7 No. 2, pp. 21-36.

[31] Damrongwongsiri, M. 2003._Modelling Strategic Resource Allocation in Probabilistic Global Supply Chain System with Genetic Algorithm'. Thesis, (PhD). University of Florida Atlantic.

[32] Esteves, J. and Bohorquez, V. (2007), "An updated ERP systems annotated bibliography: 2001-2005", Communications of AIS, No. 19, pp. 386-446

[33] Esteves, J. and Pastor, J. (2001), "Enterprise resource-planning systems research: an annotated

[34] bibliography", The Communications of the AIS, Vol. 7 No. 1, pp. 1-52.

[35] Fisher, M. L., Raman, A., McClelland, A., 2000. "Rocket Science Retailing Is Almost Here --

[36] Are You Ready?",Harvard Business Review, pp. 115-124

[37] Galbraith, J. Organization design: An information processing view. Interfaces, 4(3), 28-36, 1974.

[38] Gripsrud, G. Jahre, M. and Person, G. 2006. _Supply Chain Management- Back to future?‘.International Journal of Physical Distribution and Logistics Management. 36 (8): 643-659.

[39] Gupta,M., Kohli,A., 3Enterprise resource planning and its implications systems4, Technovation 26, 2006

[40] Holwem., Disney,S., Holmstro,J., Smaros,J., 3Supply Chain CoG, llaboration :Making Sense of the Strategy Continuum4, European Management Journal, Vol .23, No .2, , 2005

[41] Iles, A., 2007. "Seeing Sustainability In Business Operations: US And British Food Retailer

[42] Experiments With Accountability", Business Strategy \& the Environment (John Wiley \& Sons, Inc) 16, pp. 290-301 Judge, A., 1997, "The Art of Non-Decision Making and the manipulation of categories",www.uia.org/uiadocs/nondec.htm 24/10/2001.

[43] Kelly, S., Holland, P., Light, B., 2000, "A Departure from Traditional Systems Development Methodologies:Enterprise Resource Planning, ERP, Systems and the use of Process Modelling Tools", Proceedings of the 9thAnnual Business Information Technology Conference, November 3-4 1999, Manchester

[44] Lambert, D. M. and Cooper, M. C. (2000), Issues inSupply Chain Management, Industrial MarketingManagement, Vol. 29, pp. 65-83

[45] Lee,H., Whang,S., 3Information Sharing in a Supply Chain4, International Journal of Technology Management, Vol .20, No.3/4, 2009

[46] Mabert, V.A., Soni A., Venkataramanan, M.A. 2003. "Enterprise Resource Planning: ManagingThe Implementation Process", European Journal of Operational Research 146, pp. 302-314.

[47] Markus, M.L., Tanis, S.C. and van Fenema, P.C. (2000), "Multisite ERP implementations",

[48] Communications of the ACM, Vol. 43 No. 4, pp. 42-6.

[49] Moller., 3Erp :a conceptual framework for next-generation enterprise systems4, Journal of Enterprise Information Management, Vol .18, No .4, 2005

[50] Neuman, W.L. (1997), Social Research Methods: Qualitative and Quantitative Approaches, Allyn\& Bacon, Needham Heights, MA.

[51] Ngai, E.W.T., Law, C.C.H. and Wat, F.K.T. (2008), "Examining the critical success factors in theadoption of enterprise resource planning", Computers in Industry, Vol. 59 No. 6, pp. 548-64. 